\title{
Basement-Controlled Deformation of Sedimentary Sequences, Anadarko Shelf, Oklahoma
}

\author{
F. Kolawole ${ }^{1 *}$, M. Simpson Turko ${ }^{1}$, B. M. Carpenter ${ }^{1}$ \\ ${ }^{1}$ School of Geosciences, RM 710, Sarkeys Energy Center, 100 East Boyd Street, University of \\ Oklahoma, Norman OK
}

*Corresponding author: folarin@ou.edu

\section{Highlights}

- Sub-vertical faults \& mafic sills define the basement structure of the Anadarko Shelf

- Only the sub-vertical faults penetrate into the overlying sedimentary sequences

- Fault-related structural domains include deeper faulted blocks that transition upward into faulted monoclines, \& monoclinal flexure

- Basement-driven fault propagation is more efficient in driving the fault deformation to shallower depths than the intrasedimentary-driven fault nucleation and propagation

- Cumulative vertical separation curves become closely clustered at greater values as fault offset increases 


\begin{abstract}
Structures rooted in the crystalline basement frequently control the deformation of the host bedrock and the overlying sedimentary sequences. Here, we elucidate the structure of the $\sim 2 \mathrm{~km}$-deep Precambrian granitic basement in the Anadarko Shelf, Oklahoma, and how the propagation of basement faults deformed the sedimentary cover. Although the basin is foreland in origin, the gently-dipping shelf sequences experienced transpressional deformation in the Late Paleozoic. We analyze a 3-D seismic reflection dataset and basement penetrating well data in an area of $824 \mathrm{~km}^{2}$. We observe: (1) pervasive deformation of the basement by basement-bounded interconnected mafic sills, and a system of sub-vertical discontinuity planes (interpreted as faults) of which some penetrate the overlying sedimentary cover, (2) three large (>10 km-long) through-going faults, with relatively small $(<100 \mathrm{~m})$ vertical separation (Vsep) of the deformed stratigraphic surfaces, (3) upward propagation of the large faults characterized by faulted-blocks near the basement, and faulted-monoclines in the deeper sedimentary units that transition into open monoclinal flexures up-section, (4) cumulative along-fault deformation of the stratigraphy exhibits systematic trends that varies with offset accrual, (5) two styles of Vsep - Depth distribution which include a unidirectional decrease of Vsep from the basement through the cover rocks (Style-1), and a bi-directional decrease of Vsep from a deep sedimentary unit toward the basement and shallower sequences (Style-2). We find that the basement-driven propagation (Style-1) shows greater efficiency of driving the fault deformation to shallower depths compared to the intrasedimentary-driven fault nucleation and propagation (Style-2). Our study demonstrates an evolution of cumulative Vsep trends with offset accrual on the faults, and the partial inheritance of the heterogeneous intrabasement deformation by the sedimentary cover. This contribution provides important insight into the upward propagation of basement-driven faulting associated with structural inheritance in contractional sedimentary basins.
\end{abstract}

Keywords: Basement faults; Strike-slip; Transpression; Fault propagation; Structural inheritance; Intrabasement reflectors; Igneous sills. 


\section{INTRODUCTION}

Contractional basement-involved structures in sedimentary basins have been studied both in the field, geophysical datasets and through modelling experiments (e.g., Coward, 1983; Naylor et al., 1986; McClay \& Ellis, 1987; Hardy \& Ford, 1997; Harper et al., 2001; McClay, 2011; Lacombe \& Bellahsen, 2016). The nucleation and development of contractional structures are often found to be controlled by structural inheritance from the underlying crystalline basement, typically in the form of faults and fracture networks (e.g., Lowell, 1995; Lihou \& Allen, 1996; Turner \& Williams, 2004; Keller \& Stephenson, 2007; Iaffa et al., 2011), magmatic intrusions (Gwon \& Kim, 2016; Lee \& Kim, 2018), metamorphic foliation and ductile shear zones (e.g., Collanega et al., 2018). Zones of structural weakness in the basement may preferentially localize strain such that their tectonic reactivation can influence the structural architecture and deformation of the sedimentary sequences within a basin (e.g., Yonkee, 1992; Erslev \& Koenig, 2009; Kolawole et al., 2018, 2019a).

Contractional basement-involved structures are most common in foreland basins where they occur between major fold and thrust belts and the undeformed craton (e.g., Rodgers, 1987; Mitra \& Mount, 1998; Lacombe \& Bellahsen, 2016). This category of basementinvolved structures is typically characterized by a major basement-rooted fault that is overlain by a long chain of anticlinally-folded sedimentary sequences with steepened (to overturned) forelimbs and gently-dipping backlimbs (e.g., Mitra \& Mount, 1998). The associated fault may be steeply-dipping in the basement, but more shallowly-dipping in the sedimentary cover (anticlinal fault bend; e.g., Berg, 1962; Prucha et al., 1965). In other cases, the fault may be steeply-dipping at shallow basement depths, but less steep (synclinal fault bend; Mitra \& Mount, 1998) or very gentle at deeper depths (thrust; Berg, 1962; Brown, 1983; Stone, 1993). Also, the structures may develop by reverse slip, strike-slip, or a combination of both kinematics (transpression), commonly associated with flexural slip in the sedimentary cover (e.g., Stearns, 1975, 1978; Reches, 1978; Suppe, 1983; Tindall \& Davis, 1999). Additionally, the deeper sedimentary units may or may not be welded to the underlying crystalline basement, each case producing distinct structural styles of predictable mechanical deformation (Mitra \& Mount, 1998).

Above a propagating contractional basement-rooted fault, a major fault-propagation fold develops with a triangle deformation field that converges downwards towards the tip of the basement fault trace (e.g., Erslev, 1991; Hardy \& Ford, 1997; Mitra \& Mount, 1998; Hardy \& Allmendinger, 2011). This triangular deformation field above the basement fault represents a 'halo zone' of fault influence within which intense penetrative contractional deformation may be expected (e.g., Mitra \& Mount, 1998; Burberry \& Lowe, 2019). Furthermore, the associated styles of deformation may be influenced by a combination of position relative to the basement fault trace (i.e. height of the unit above the basement) and the mechanical behavior of the various rock units (Reches, 1978).

Most studies of contractional basement-involved deformation of sedimentary sequences have focused on faults that accommodate dominant thrust kinematics. There is limited 
understanding of the strain distribution and structural styles associated with those that accommodate transpressional kinematics (e.g., Schmidt \& Hendrix, 1981, Tindall \& Davis, 1999). Although these little-understood faults have accommodated a minor component of reverse slip, the net slip is dominated by a larger component of strike-slip. A few attempts to address this problem employed a numerical modelling of the geometrical modification of stratigraphic surfaces resulting from transpressional fault displacement (Anderson et al., 2015). Nevertheless, robust numerical models should incorporate detailed observations of the structural and mechanical controls.

Here, we will investigate intrabasement deformation, and structural inheritance of the basement by analyzing the overlying sedimentary sequences in the transpressionallydeformed Anadarko Shelf, Oklahoma (Figure 1a). We will first analyze intrabasement deformation, and subsequently, show how components of the deformation are propagated up into the sedimentary cover. Our study will reveal a pervasive deformation of the granitic basement by: (a) basement-bounded mafic igneous sills; and (b) sub-vertical discontinuity planes interpreted as faults, some of which penetrate into the overlying sedimentary cover. We will show that deformation along the basement fault is propagated up over three structural domains: 1) basal faulted-block, 2) faulted-monocline that transitions into 3) monoclinal flexure. Also, our analyses will reveal two styles of Vertical Separation - Depth relationships, which include a basement-driven unidirectional fault propagation (Style-1), and an intrasedimentary-driven fault nucleation and bi-directional propagation (Style-2). Further, we will demonstrate that along-fault deformation of affected stratigraphic surfaces exhibits systematic trends that varies with offset accrual. We will show that the basementdriven fault propagation has greater efficiency of propagating the fault-related deformation to shallower depths compared to the intrasedimentary-driven nucleation and propagation. Overall, this contribution will show that the sedimentary deformation of the Anadarko Shelf represents a partial inheritance of the heterogeneous intrabasement deformation. The results presented here will provide insights into the upward propagation of basementdriven faulting associated with structural inheritance in contractional sedimentary basins.

\section{GEOLOGICAL SETTING}

\subsection{The Precambrian basement}

The Precambrian basement of Oklahoma is part of the 1.35-1.4 Ga Southern Granite-Rhyolite Province of central U.S. (Figure 1a inset; Thomas et al., 1984; Bickford et al., 2015). Studies in Oklahoma indicate that it is dominated by granitic and rhyolitic rocks (Figure 1b; Denison, 1981; Denison et al., 1984; Shah \& Keller, 2016). In southern Oklahoma, where this basement is most extensively exposed, there is a pervasive occurrence of mafic sheet intrusions in the granites (Denison, 1995; Lidiak et al., 2014). The intrusions have a dominant NW-SE strike (Denison, 1995; Lidiak et al., 2014), parallel to a prominent trend of fracturing in the granitic basement (Kolawole et al., 2019b). Geochronological investigations suggest Mesoproterozoic to Cambrian ages for the intrusions (Denison, 1995; Lidiak et al., 2014). 
By 1109-1094 Ma, the North American craton began to split apart (Cannon, 1994) along the Keweenawan Rift (Mid-Continent Rift) where the NNE-SSW-striking western arm of the rift propagated southwards from Lake Superior all the way through north-central Oklahoma (Figures 1a inset, 1b; Van Schmus \& Hinze, 1985; Stein et al., 2018). By 1100 Ma, westdirected compressive tectonic stresses from the Grenville Orogeny in the east led to the closing of the rift with reverse-faulting of the previously extended crust (Cannon, 1994). The closing of the rift was followed by the widespread erosion of the basement surface in the Late Proterozoic, which resulted in the hummocky morphology pattern of the basement surface (Elebiju et al., 2011; Kolawole et al., 2019b).

\subsection{The Anadarko Basin}

The Anadarko Basin is one of the deepest basins in the United States ( $>12 \mathrm{~km}$ of sedimentary fill), and its complex subsidence history can be divided into three major phases: (1) Late Proterozoic to Mid-Cambrian aulacogen development, (2) Late Cambrian through Early Mississippian post-rift thermal subsidence (the southern Oklahoma trough), and (3) Late Mississippian to Early Permian tectonic contraction associated with development of the Anadarko intracratonic foreland basin on the northwestern flank of the trough.

In the Late Proterozoic to Middle Cambrian, a NW-SE - trending rift system developed in southern Oklahoma and is associated with the voluminous emplacement of intrusive and extrusive igneous rocks (e.g., Figure 2a; Brewer et al., 1983). This is the last igneous tectonic event that affected the south-central United States region (e.g., Whitmeyer \& Karlstrom, 2007). Through the Ordovician to the Mississippian, the Oklahoma basement subsided, allowing for the deposition of thick sedimentary sequences, marking the onset of Anadarko Basin development (e.g., Figures 2a-c; Johnson, 2008). By the Late Mississippian through the Pennsylvanian, SW-directed compressive stresses from the Appalachian Orogeny in the east led to crustal shortening and folding in southern Oklahoma. This tectonic compressional event caused an inversion of the NW-SE Cambrian rift system in south and SW Oklahoma, and the development of a NE-trending fold thrust belt in SE Oklahoma (e.g., Figures 1a, 2a, c; Powers, 1928; Brewer et al., 1983; Keller \& Stephenson, 2007; Simpson, 2015). The inverted rift system is known as the Southern Oklahoma Aulacogen, SOA (Wichita and Arbuckle Uplifts), and the fold thrust belt is known as the Ouachita Mountains (Figures 1a, 2c).

The crustal loading from the accelerated uplift of the SOA and Ouachita domains in the Pennsylvanian resulted in the syn-tectonic down-warping of the basement in SW and SE Oklahoma, forming the present-day Anadarko and Arkoma foreland basins (Figures 1a, 2c; e.g., Brewer et al., 1983; Johnson, 2008; Simpson, 2015). As the Anadarko basin foredeep subsided in the south, a broad, gently dipping shelf area developed in the central and northern Oklahoma, known as the Anadarko Shelf (Figure 1a). As the shelf area developed, the tectonic stresses induced widespread transpressional deformation in central and northern Oklahoma, which include the development of several NE, NW, and $\sim \mathrm{N}$-trending sub-vertical strike-slip and reverse faults that root into the basement and penetrate the 
Paleozoic sedimentary sequences (Dolton \& Finn, 1989; McBee, 2003a, 2003b; Gay, 2003; Gay, 1999; Liao et al., 2017). Among these transpressional strike-slip structures, the Nemaha Fault (and Uplift), Wilzetta Fault, Whitetail Fault, Keokuk Fault, El Reno Fault, Galena Township Fault, Stillwater Fault are most prominent (Figure 1a; Gay, 2003; McBee, 2003a, 2003b; Liao et al., 2017; Chopra et al., 2018a).

2.2 The stratigraphy of the Anadarko Shelf and its regional significance

The stratigraphy of the Anadarko Shelf (Figures 2a-c) consists of the basal Precambrian basement with an erosional top (Benson, 2014), above which Ordovician to Mississippian carbonate, shale and sandstone sequences were unconformably deposited (e.g., Johnson, 1989; Van der Pluijm \& Catacosinos, 1996). These units generally thicken southwestwards towards the Anadarko Foredeep (Figure 2c), and due to multiple episodes of subaerial exposure of the units, several unconformities exist between the packages. Within the deeper sedimentary sections of the study area, the Arbuckle Group is thickest and lies directly on the Top-Basement erosional surface (Figures 2a-b). Recently, the Anadarko Shelf had been in the spotlight for two reasons. First, the area hosts the occurrence of sporadic and widespread wastewater injection-induced seismicity (e.g., Kolawole et al., 2019b). The Arbuckle Group is the primary zone of wastewater disposal, and the Precambrian Basement hosts most of the resulting induced seismicity (e.g., Kolawole et al., 2019). Second, the shelf area hosts the STACK ("Sooner Trend, Anadarko, Canadian and Kingfisher") and Mississippi Lime Plays, which are currently some of the most active unconventional hydrocarbon exploration plays in North America (e.g., Yee et al., 2017). Exploration target zones include the Woodford, Hunton, Morrow, Oswego, Mississippian and Osage stratigraphic intervals (Figure 2a-b; Droege \& Vick, 2018).

\section{DATA AND METHODS}

\subsection{Seismic data set and fault interpretation}

To investigate subsurface faulting in the Anadarko Shelf, Oklahoma, we utilize a post-stack time migrated 3-D seismic reflection survey covering an area of $824 \mathrm{~km}^{2}$ in Kingfisher County, Oklahoma (Figures 1a-b, 3a; courtesy of TGS). The seismic dataset has a dominant frequency of $65 \mathrm{~Hz}$ in the sedimentary cover and $\sim 56 \mathrm{~Hz}$ within the crystalline basement. For the sedimentary section, we assume a reasonable average velocity of $\sim 5300 \mathrm{~ms}^{-1}$ (well log dynamic velocity for the Mississippian Meramec Fm., 2 - $2.5 \mathrm{~km}$ deep). Experimentally constrained P-wave velocity for the Oklahoma basement at effective confining pressure relevant for the interval of interest (50-60 MPa) is $6000 \mathrm{~ms}^{-1}$ (Kibikas et al., 2019). These frequencies and velocities imply a vertical resolution of $\sim 21 \mathrm{~m}$ (sedimentary section) to $\sim 27$ $\mathrm{m}$ (in the basement) for the dataset. Through a student academic subscription to the IHS well database, we obtain access to raster wireline logs for basement penetration Well-KF1 which we digitize in the IHS Petra Software prior to integration with the seismic data. We perform 
a well log to seismic tie using the digitized Well-KF1 logs and logs from other basement well penetrations within the study area For the log to seismic tie, we first create a velocity model approximation from the wells, which we then use to convert the seismic amplitude volume from time to depth. The log to seismic tie process involves a statistical wavelet extraction around multiple wells. The comparison of the average wavelet from each of the wells with a zero-phase wavelet indicates the difference in the phase of seismic traces. The seismic data was initially found to be $-95^{\circ}$ out of phase and was zero-phased prior to stratigraphic interpretation. Due to proprietary data restrictions, most of the seismic images are here in presented in the minimum phase. Our interpretation workflow consists of a manual interpretation and gridding of the Top-Basement ( $\sim 3.2 \mathrm{~km}$ depth) and Top-Arbuckle $(\sim 2.7$ $\mathrm{km}$ depth) surfaces. Further, we interpret a surface along a broad (347 km²) deep-seated (> $6 \mathrm{~km}$ depth) intrabasement reflector (IBR) within the survey. Studies of intrabasement reflectors in sedimentary basins of similar basement depth have used seismic reflection data to investigate structural inheritance (e.g., Reeve et al., 2014), thus validating the feasibility of our approach. We envision that fault mapping at the Top-Basement and Top-Arbuckle surfaces provide first order assessment of basement fault connectivity with the sedimentary cover. Analysis of sub-vertical discontinuity planes and related lineaments along the IBR surface provide an assessment of the trends of brittle deformation in the basement, and the depth extent of the major Top-Basement faults. For our surface horizon mapping, we pick the zero-crossing of the seismic reflectors near the target stratigraphic surfaces.

To better resolve structural deformation along the interpreted surfaces, we compute structure-oriented seismic attributes (e.g., Chopra \& Marfurt, 2005, 2006; Infante-Paez \& Marfurt, 2017) from the seismic volume and extract the attributes onto the mapped surfaces. Primarily, we use 3-D Curvature and Similarity seismic attributes. The most-positive curvature (k1) resolves up-warped zones/upthrown blocks and the most-negative curvature (k2) highlights down-warped areas/downthrown blocks. Thus, fault zones with small vertical offsets and subtle structural flexures, often typical of strike-slip faults, are well resolved on the interpreted surfaces. The Energy Ratio Similarity (a measure of coherence) attribute is an edge-detection attribute that resolves zones of discontinuity along reflectors. Thus, the Energy Ratio Similarity attribute reveals fault damage zones as lineaments of low coherence relative to flanking blocks of higher coherence (Chopra \& Marfurt, 2005). We compute the seismic attributes with the Attribute Assisted-Seismic Processing and Interpretation (AASPI) software package from the University of Oklahoma. We perform the attribute extraction and co-rendering with Petrel Software application.

Additionally, we quantify lineament distribution on the Top-Arbuckle, Top-Basement and intra-basement reflector (Top-Intra-basement reflector) surfaces by calculating Areal Lineament Density $\left(\mathrm{Ld}_{d}\right)$ and Areal Lineament Intensity $\left(\mathrm{L}_{\mathrm{I}}\right)$. $\mathrm{L}_{\mathrm{d}}$ is the ratio of total lineament count to the area of the stratigraphic surface; and $L_{I}$ is the ratio of sum total of lineament lengths to the area of the stratigraphic surface. We assess the extent of the deformation field above the basement faults, we assess the dip isogon patterns (Ramsay, 1967; Ramsay \& 
Huber, 1987) along the large, through-going faults. Within the bounds of this deformation field, we measure the vertical separation of the deformed stratigraphic contacts.

\subsection{Estimation of three-dimensional distribution of vertical separation (Vsep) along the} faults

The low magnitude of the vertical component of fault offset and limited seismic resolution make it difficult to resolve the footwall and hanging wall cut off markers on the faults, and consequently, difficulty in assessing fault throw. Therefore, to quantify the magnitude and 3D distribution of deformation along the large $(>10 \mathrm{~km})$ through-going faults in the seismic dataset, we estimate the variation of vertical separation of seismic reflectors along the faults (Figures 3a-c). Here, we define 'vertical separation (Vsep)' as the vertical difference between the depth to a horizon in the hanging wall of a fault and the depth to the same horizon in the footwall of the fault (Figures 3b-c). Likewise, this definition includes the vertical difference between the depth to a horizon in the anticlinal segment of a monocline and the depth to the same horizon in the associated syncline. Since well log-to-seismic tie allows us to constrain the major stratigraphic packages, the similarity and continuation of reflection packages across the faults helped to ensure an interpretation of the same horizon either side of the fault. We assume that the measured Vsep values represent only the apparent vertical component of fault displacement and the associated stratigraphic flexure. Thus, we use this term, Vsep, to quantify vertical separation at faulted blocks, faulted monoclines and faultcontrolled monoclinal flexures.

At $2 \mathrm{~km}$ intervals along two representative faults, we measure the Vsep of six (6) stratigraphic surfaces where the data quality permits (Figures 3a-b). These surfaces include the Top-Basement (Top-Precambrian), Top-Lower Ordovician (Top Arbuckle Group), TopDevonian (Top Hunton Group), a Mississippian reflector (strong, laterally-continuous reflector within the Mississippian section), Top-Mississippian (Top-Chester Group), and a Pennsylvanian reflector (strong, laterally-continuous reflector within the Pennsylvanian section). For these measurements, we use the zero-crossing of the seismic reflectors along the mapped surfaces as offset markers. Due to proprietary data limitations, we do not have Vsep measurements at the structural depth levels of the IBRs that were cut by the faults. We have provided the spreadsheets of our Vsep measurements as supplementary information files of this publication.

\subsection{Basement well penetration data}

To constrain our interpretation of aspects of the structure of the crystalline basement, we obtain wireline logs (courtesy of TGS) and drill cuttings (courtesy of Oklahoma Petroleum Information Center) from the basement penetration well in Kingfisher County, here-in referred to as Well-KF2 (Figure 2b). Further, we utilize X-Ray Diffraction (XRD) and X-Ray Fluorescence (XRF) analyses of the drill cuttings to understand the mineralogical and 
chemical compositions of the drill cuttings (courtesy of the Chesapeake Energy Reservoir Technology Center), and thus, identify the associated lithological characteristics of the basement. Additionally, using standard techniques, we model a synthetic seismogram using the sonic and density wireline logs available from Well-KF2 and other basement penetration wells in the study area. Due to proprietary restrictions, both the sonic and density logs used are not shown here. We have provided the spreadsheets of the XRD and XRF geochemical data as supplementary information files of this publication.

\section{RESULTS}

Below, we present our results in a bottom-up sequential manner, from the deep intrabasement domain, up through the Top-Basement, Top-Arbuckle, and shallower sedimentary formations.

\subsection{The intrabasement reflectors (IBR)}

\subsubsection{Geophysical and geological observations}

The 3-D seismic dataset shows distinct, systematic patterns of reflection packets within the crystalline basement, here-in referred to as intrabasement reflections (IBR) (see representative seismic section in Figure 4a). The original seismic dataset (minimum phase) shows that each of the IBRs are characterized by a reflection packet consisting of a troughpeak-trough wave-train (top panel in Figure 4b). However, the zero-phase seismic volume (lower panel in Figure 4b) show that the IBR reflection packet consists of a peak-troughpeak wave-train. The IBRs comprise of gently-dipping systematic sets of relatively high amplitude reflectors that appear to cross-cut, but not offset, other intra-basement reflections. Through-out the seismic volume, the IBRs interconnect, commonly terminate at the Top-Basement interface (e.g., yellow X-symbols in Figure 4a), and show prominent trends along NNE-SSW (ESE-dipping), E-W (N- and S-dipping), NW-SE and NE-SW (SEdipping). Visible in the uninterpreted representative seismic section (Figure S1a) and shown in the interpreted version (Figure 4a), we observe distinct geometrical interactions between the IBR segments. These interactions include: 1) simple truncation and/or vertical juxtaposition of the segments by sub-vertical discontinuity planes (IBR step), some of which extend upward and offset the Top-Basement and shallower reflectors; 2) IBR bridge structures characterized by a deeper segment overtopped by an approaching segment in which the deeper segment terminates at a sub-vertical discontinuity plane; 3) faulted IBR bridge structures in which both the deeper and overtopping IBR segments are truncated or offset by a sub-vertical discontinuity plane. We delineate the vertical extents and geometry of the discontinuity planes by the vertical stacking of abrupt truncations of IBRs within the seismic sections.

The zero-phase seismic dataset (lower panel in Figure 4b), which by standard practice is ideal for geological interpretation, shows that the upper contact of the IBRs is defined by an increase in acoustic impedance contrast, suggesting a rock that is denser than the host 
granite. Wireline logs, drill cuttings and geochemical analyses from basement penetration Well-KF2 within the study area (Figures $2 \mathrm{~b}, 4 \mathrm{c}$ ) provide additional insight into the lithological composition of the IBRs. Overall, the $120 \mathrm{~m}$-deep basement interval, the wireline logs (Figure 4c) show high Gamma ray, high Resistivity, moderate Neutron and Density Porosity, and low P.E. baseline signatures. However, there exists two distinct intervals (17 $\mathrm{m}$ and $1.5 \mathrm{~m}$-thick; yellow arrows in Figure 4c) that show abrupt excursions from these baselines. The two intervals are characterized by very low Gamma ray and Resistivity values, high P.E. values, and Density - Neutron log crossovers. These two zones of abrupt excursions of the wireline logs clearly indicate distinct rock units within the crystalline basement.

A synthetic seismogram model of the intrabasement layer reflectivity show a strong positive reflection coefficient at the top contact of the 17-m thick layer (Figure 4c). Drill cuttings from a zone above (Sample A), within (Sample B), and below (Sample C) the intra-basement layers show that the distinct intrabasement unit is characterized by a rock that has a darker coloration compared to the host lighter-colored rock. XRD (Figure 4d) and XRF (Figures S1bc) geochemical analyses of the three samples indicate that overall, the crystalline basement is dominated by a host rock that is rich in orthoclase feldspar and quartz (Samples A and C). Whereas, the intrabasement layer (Sample B) is dominantly made up of plagioclase feldspar, amphibole, illite, smectite and augite minerals, and is deficient in orthoclase feldspar and quartz (Figure 4d) and the associated elements (Figures S1b-c).

\subsubsection{Structure of a mapped IBR}

We carefully mapped the most extensive $\left(347 \mathrm{~km}^{2}\right)$ IBR within the seismic survey, located between 6.5-8.5 km depth (Figures 5a-d). The surface is undulating, generally shallow in the west $(<6.9 \mathrm{~km})$ and transitions across a N-S topographic gradient near the center of the survey to deeper depths ( $>7.6 \mathrm{~km}$ ) in the east. The deepest part of the IBR surface is a NWtrending narrow (2.8-6.5 km-wide) region that extends from the southeast corner of the mapped area towards the center (Figure 5a). An overlay of Top-Basement faults shows a striking coincidence of major fault F1 with the central N-S topographic gradient (red arrows in Figure 5a) and F3 with the NW-trending deepest area along the IBR. An extraction of the Energy Ratio Similarity attribute onto the surface (Figure $5 \mathrm{~b}$ ) shows a high density of rectilinear discontinuity lineaments of low energy which show dominant NW-SE trend with $308^{\circ} \pm 7$ mean trend, and a minor N-S $\left(010^{\circ}\right)$ trend (Figure $5 \mathrm{c}$ ). We also observe that some of

the rectilinear low energy attribute lineaments correspond to segments of the interpreted Top-Basement faults (Figures 5d, S2).

\subsection{Faulting at the Top-Basement, Top-Arbuckle and shallower sedimentary sequences}

The interpreted Top-Basement (Figures 6a) and Top-Arbuckle (Figures 6b) structure maps show marked resemblance in that the major fault traces and concentric structural highs are co-located. Both structure maps and their co-rendered seismic attributes show coincidence 
of major fault lineaments (red arrows in Figures 6a-b, S3a-c, S4a-b). Additionally, a major basement high on the eastern part of the Top-Basement surface (Figure 6a) is coincident with a structural dome at the Top-Arbuckle surface (Figure 6b). The two surfaces show three large faults (F1, F2 and F3) with lengths greater than $10 \mathrm{~km}$. Fault F1 strikes $012^{\circ}$ and dips west, F2 strikes $031^{\circ}$ and dips NNW, and F3 strikes $296^{\circ}$ and dips SSW. Along these faults, we do not observe any significant changes in thickness of stratigraphic packages within the intervals analyzed (i.e. no observed growth strata in the Pre-Pennsylvanian strata). The fault segments commonly show steeper dips in the sedimentary cover than in the basement. For example, F3 dips $68^{\circ}$ in the basement, and $88^{\circ}$ in the sedimentary cover (Figure 6c). An integration of the structural attribute maps allows us to better resolve the geometry of the large faults as well as smaller offset discontinuity lineaments at both the Top-Basement and Top-Arbuckle surfaces (Figures S3a-c, S4a-b).

As a first order approximation of propagation of brittle deformation from the basement through the sedimentary sequences, we first compare the density and intensity of discontinuity lineaments observable on the mapped surfaces (Figure 6d). On the deepseated IBR surface $\left(\sim 7.5 \mathrm{~km}\right.$ depth), we estimate an areal lineament density of $0.458 \mathrm{~km}^{-2}$ and areal lineament intensity of $0.634 \mathrm{~km}^{-1}$. Whereas, at the Top-Basement surface $(\sim 3.2 \mathrm{~km}$ depth), we estimate an areal lineament density of $0.145 \mathrm{~km}^{-2}$ and areal lineament intensity of $0.355 \mathrm{~km}^{-1}$. At Top-Arbuckle surface ( $2.7 \mathrm{~km}$ depth), we estimate an areal lineament density of $0.078 \mathrm{~km}^{-2}$ and areal lineament intensity of $0.256 \mathrm{~km}^{-1}$. Overall, the deeper basement appears to host a larger density and intensity of discontinuity lineaments relative to the Top-Basement and Top-Arbuckle depth levels (Figure 6d).

A closer look at the co-rendered seismic attributes along the large faults (Figures 6c, S3a-c, S4a-b) provide insight into the vertical change in the geometry of fault deformation along the faults. The energy ratio similarity attribute map (Figure S3a) shows discontinuous lineaments that coincide with short segments of the large faults and a few other fault lineaments on the basement surface. The co-rendered $k 1-k 2$ curvature maps of the TopBasement surface (Figure S3b) show adjacent lineaments of upthrown and downthrown blocks that coincide with the large faults. Using F3 as a representative fault, Figures $6 \mathrm{c}$ and S3c show a fault structure that comprises of an upthrown block ( $k 1$ lineament) adjacent and parallel to a downthrown block ( $k 2$ lineament), both separated by a distinct discontinuity plane (low energy lineament). Similarly, at the Top-Arbuckle surface, each of the large faults show a lineament of up-warped/anticlinal flexure $(k 1)$ adjacent and parallel to a lineament of down-warped/synclinal flexure $(k 2)$ separated by a distinct fault plane (low-coherence lineament) (Figures S4b). Overall, the Top-Basement reflector show simple offset and little to no folded geometry across the large faults, whereas the Top-Arbuckle shows both offset and strongly folded geometry (cross-sections in Figures 6c and 7a).

More interestingly, farther up-section of the Top-Arbuckle surface, we observe that the seismic reflectors show further transitions in geometry that is different from that of the TopBasement and Top-Arbuckle (Figure 7a). Again, using F3 as a representative fault, the dip isogon pattern (Figure 7b) describes a simple geometry between the Top-Basement and Top 
-Arbuckle surfaces primarily because of the lack of folding of the Top-Basement. However, the interval between the Top-Arbuckle and Top-Hunton surfaces show tightly-folded units with sub-parallel isogon contours that transition into less-tightly folded intervals between the Top-Hunton and Top-Chester surfaces. Above the Top-Chester, both the isogon contours and stratigraphic surfaces describe predominantly open to gentle folds (Figure 6b).

\subsection{3-D distribution of vertical separation (Vsep) along the large faults}

4.3.1 Vsep and cumulative Vsep versus distance along-strike of the large faults (Vsep-D and CVsep-D)

As shown in Figures 4-7, the three large faults in the dataset (faults F1, F2 and F3) deform the mapped broad IBR, Top-Basement surface and penetrate the sedimentary sequences. The zone of flexural curvature around these faults (i.e. the deformation field bounded by the $0^{\circ}$ dip isogons) describes a triangular deformation zone that can be as large as $1.7 \mathrm{~km}^{2}$ (fault F3, Figure 7b). Within this flexural zone, the distribution of vertical separation (Vsep) reveals important trends described below.

The Vsep-D plots along faults F1 and F2 show systematic variation of fault-related stratigraphic deformation along-strike of the faults (Figures 8a-b). Although the measured Vsep values along F1 are less than $100 \mathrm{~m}$, they are highest in the north $(96.1 \mathrm{~m})$ and decreases southwards toward the intersection zone of the major faults (Figure 8a). At the intersection zone, there is little or no change in the continuity or geometry of the reflectors. To the south of the intersection zone, vertical separation is evident, although by only a small amount ( $<25 \mathrm{~m}$, Figure 8a). Similarly, along F2, Vsep is highest in the north $(\sim 31 \mathrm{~m})$ and decreases southwards along the fault towards the zone of intersection with faults F1 and F3 (Figure 8b). Further, the distribution of cumulative Vsep with distance (CVsep-D) for both faults (Figures 8c-d, S5a-b) show spatial clustering of the curves. For both F1 and F2, The Top-Basement and Top-Arbuckle curves cluster tightly at relatively higher values, whereas the curves for the shallower stratigraphic surfaces cluster at relatively moderate to lower values $\left(<0.75 \cdot\right.$ CVsep $\left._{\max }\right)$ but the patterns differ markedly between the two faults. Along F1, most of the shallow strata curves cluster closely within the region between the $0.25 \cdot \mathrm{CV}$ sep $_{\text {max }}$ and $0.75 \cdot$ CVsep $_{\max }$ boundaries, although the Pennsylvanian reflector plots near the lower boundary (Figure 8c, S5a). Along F2, most of the shallow strata CVsep-D curves cluster within or just above the region below the $0.25 \cdot{ }^{C} V_{s e p}$ max boundary (Figures $8 \mathrm{~d}, \mathrm{~S} 5 \mathrm{~b}$ )

\subsubsection{Vsep versus depth (Vsep-Z) along the large faults}

The Vsep-Z plots for F1 and F2 (Figures 9a-b) show that overall, from the Top-Basement up through the Pennsylvanian units, Vsep decreases with shallowing depth. At all the measurement locations on F1 and F2, Vsep is highest at deeper depths (Top-Basement and Top-Arbuckle) and least at the shallowest depths (Top-Chester and Pennsylvanian 
reflector). Overall, the Vsep-Z distribution along these faults describes two styles, here in referred to as Style-1 and Style-2 (Figures 9c-d). Style-1 refers to a Vsep-Z distribution in which Vsep increases linearly with depth down through the Top-Basement surface (Figure 9c). We observe the Style-1 pattern of Vsep distribution at L1, L2 and L5 along fault F1, and L2, L4, L5 and L6 along fault F2. Style-2 consists of a Vsep-Z distribution in which Vsep is highest within the deeper sedimentary units and decreases upwards (through the shallower units) and downwards to the basement (Figure 9d). We observe the Style-2 pattern of Vsep distribution at L4, L6 and L10 along fault F1, and at L1 along fault F2.

Further, for both propagation styles, we assess the quantitative relationships between the magnitude of fault deformation at the inferred nucleation depths and the efficiency of upward propagation of the deformation. At all the measurement locations, the Top-Chester is the shallowest stratigraphic surface for which we have the most Vsep measurements along the two faults. Thus, for the Style-1 trends (in Figures 9a-b), the plot of Vsep at the TopBasement (Vsepтв) versus Top-Chester (Vsepтс) surfaces (Figure 10a) describes the relationship:

$$
\mathrm{Vsep}_{\mathrm{TB}}=2.21 \mathrm{Vsep}_{\mathrm{TC}}+2.48
$$

Similarly, for the same Style-1 measurements, the plot of Vsep at the Top-Arbuckle (VsepтA) versus Top-Chester (Vsepтс) surfaces describe the relationship:

$$
\text { Vsep }_{\mathrm{TA}}=1.81 \mathrm{Vsep}_{\mathrm{TC}}+1.72
$$

Whereas, for the Style-2 measurements, the plot of Vsep at the Top-Arbuckle (Vsepта) versus Top-Chester (Vsертс) surfaces describe the relationship:

$$
\text { Vsep }_{\mathrm{TA}}=3.33 \mathrm{Vsep}_{\mathrm{TC}}+4.72
$$

\section{DISCUSSION}

5.1 Intrabasement deformation and structural inheritance in the Anadarko Shelf

The analyzed seismic dataset shows distinct interconnected IBRs that commonly terminate at the Top-Basement erosional surface, giving the Anadarko Shelf basement a layered appearance (Figure 4a). This character is consistent with previous observations of enigmatic reflection packets in seismic reflection datasets from other parts of the basin (Elebiju et al., 2011; Chopra et al., 2018b; Kolawole et al., 2019b). Wireline logs and drill cuttings retrieved from a basement penetration Well-KF2 in our study area provide the first ground-truthing of the physical, mineralogical, and chemical composition of the IBRs (Figures 4c, S1b-c). The well data show that the host granitic basement is layered by a distinct rock that is deficient in potassium feldspar, relatively more conductive and composed of dark-colored minerals (Figures 4c-d). Our geochemical analyses (XRD and XRF; Figures 4d, S1b-c) show mineral assemblages that indicate a host felsic (granitic) crystalline basement (Samples A and C) and a mafic (diabase/gabbro) intra-basement rock units (Sample B). These results provide, for 
the first time, physical and geochemical evidence of mafic origins for the intra-basement reflectors in north-central Oklahoma. It is possible that the granitic drill cuttings (Samples A and C) include pegmatitic sheet intrusions, however there is no strong evidence for this currently. Additionally, the zero-phased seismic data wavelet (Figure $4 \mathrm{~b}$ ) and synthetic seismogram model from wireline logs (Figure 4c) show increased impedance across the topIBR contact, suggesting that the rock defining the IBR is denser than the host granite. Thus, the geometrical, geological and geophysical evidences presented here lead us to interpret that the IBRs beneath the Anadarko Basin are Precambrian gabbro and/or diabase sills that intruded the granite-rhyolite basement. Further, the basement-bounded character of the IBRs suggest that they most-likely intruded the granitic basement sometime between the Mesoproterozoic (emplacement of the host Granite-Rhyolite Province) and the Ordovician Arbuckle carbonate units.

As shown in Figures 2a-c, a Precambrian crystalline basement unconformably underlie the Phanerozoic sedimentary cover of the Anadarko Shelf. This basement is part of the 1.35 1.48 Ga Granite-Rhyolite Province of central and Eastern U.S. (CEUS), mapped as an extensive juvenile terrane which extends from southwestern United States through the midcontinent (e.g., Figure 1a inset; Thomas et al., 1984; Whitmeyer \& Karlstrom, 2007; Bickford et al., 2015). Legacy deep seismic imaging also shows intrabasement reflectors (IBR) in the Cambrian basement of the Southern Oklahoma Aulacogen (SOA; Figure 1a; 2c), interpreted to be gabbro sills (Widess \& Taylor, 1959) or mylonitic segments of deep thrust detachment faults (Brewer et al., 1983). Similar features have been reported in the basement of other areas in CEUS of similar age and tectono-thermal history as the basement of the Anadarko Shelf. These include north Texas (e.g., Font, 2003), southwest Texas (Kim \& Brown, 2019), and the Illinois Basin (McBride et al., 2016,2018). However, due to the relatively deep burial of this basement in most of the places, its detailed structure and influence of its structural inheritance on the deformation of the phanerozoic cover sequences are poorly understood. Here, we present one of the first results showing a ground truthing evidence of the composition of the widely observed intrabasement seismic reflectors across the Mesoproterozoic Granite-Rhyolite Province of central-eastern US.

In addition to the intrusion of sills as a form of basement deformation, we also observe the pervasive occurrence of sub-vertical discontinuity planes that terminate or offset segments of the IBRs (e.g., Figures 4a, S1a). Some of these discontinuity planes extend up into the cover rocks, offsetting and deforming both the Top-Basement surface and the sedimentary sequences (e.g., Figures 4a, 5d, 7a, S1a). However, we also find that although other segments of the discontinuity planes are well defined in the basement, they do not reach or deform the Top-Basement reflector (Figure 4a). We interpret these sub-vertical discontinuity planes as fault planes that constitute brittle deformation in the basement.

Some striking characteristics of these discontinuity planes are evident and may provide insight on their origin. First, although some of the discontinuity planes define IBR steps and offset IBR bridges (Figure 4a, S1a), we observe cases of IBR bridge interactions where the deeper segment terminates at a sub-vertical discontinuity plane and both of which are 
overtopped by an approaching IBR segment. An example of this interaction is labelled "IBR Bridge" in Figure 4a. Second, lineaments of these discontinuity planes that cut the mapped IBR surface (Figure 5b) show a dominant trend of $308^{\circ}$ (Figure 5c). This trend is remarkably consistent with: 1) the strike of one of the largest faults in the study area (Fault F3), 2) a prominent fracture trend $\left(308^{\circ} \pm 3.6\right)$ in the outcrops of this basement in southern Oklahoma (Kolawole et al., 2019b), 3) the dominant trend of Proterozoic-Cambrian mafic dikes $\left(300^{\circ}\right)$ in the outcrops of the basement (Denison, 1995; Lidiak et al., 2014), and 4) a prominent trend of recent seismogenic basement faulting in the Anadarko Shelf $\left(297^{\circ} \pm 3.6\right)$ (Schoenball \& Ellsworth, 2017; Kolawole et al., 2019b). This common NW $\left(\sim 300^{\circ}\right)$ trend, a conjugate NE $\left(\sim 240^{\circ}\right)$ trend, and a secondary N-S trend has been interpreted to be dominant structural trends in the Precambrian basement of Oklahoma (Denison, 1995; Kolawole et al., 2019b).

Therefore, considering the character and trends of these sub-vertical discontinuity planes, our preferred interpretation is that they represent fault planes within the Precambrian basement that possibly predate the emplacement of the IBRs. Further, we interpret that the extension of some of the discontinuity planes up-section and the associated deformation of the Top-Basement and shallower stratigraphic surfaces represent a reactivation of this brittle structures during the Phanerozoic. Additionally, the comparison of lineament density and intensity between the depth levels (Figure 6d) suggest that fault connectivity between the basement and the sedimentary section is defined by a relatively small proportion of the basement faults that are propagated up across the Top-Basement surface. Although preexisting intrabasement mafic sheet intrusions can control faulting in contractional tectonic settings (Gwon \& Kim, 2016; Lee \& Kim, 2018), our seismic dataset does not show any evidence for this in the Anadarko Shelf. However, we do not rule out the possibility. Both sub-horizontal (sill) and sub-vertical (dike) mafic sheet intrusions occur in the outcrop exposures of the Oklahoma basement, where the sills commonly branch out from the dikes (e.g., Lidiak et al., 2014; Kolawole et al., 2019). However, the absence of dike-related reflections in our seismic dataset may be explained by the inherent difficulty of seismic reflection imaging of dikes (e.g., Zaleski et al., 1997; Wall et al., 2010; Phillips et al., 2018). Overall, based on our dataset, we infer that at least the brittle component of the intrabasement deformation was inherited by the sedimentary sequences of the Anadarko Shelf.

\subsection{Propagation of fault deformation into the sedimentary sequences}

\subsubsection{Implied kinematics of the large faults}

The seismic sections do not show the presence of growth strata across the analyzed large faults. Along the mapped surfaces (Top-Basement and Top-Arbuckle; Figures 6a-b, S3, S4), the faults do not exhibit pervasive secondary faulting patterns (e.g., Reidel and flower structures) that may be used as fault kinematic indicators. Nevertheless, to understand the most probable sense of movement on the faults, the following should be emphasized: 
(1) The geometry (N, NNE and WNW-ESE strikes, and sub-vertical dips) of the faults are consistent with those of previously studied large fault zones nearby on the Anadarko Shelf. Among these structures, the Nemaha Fault (and Uplift), Wilzetta Fault, Whitetail Fault, Keokuk Fault, El Reno Fault, Galena Township Fault, Stillwater Fault are most prominent (Figure 1a; Dolton \& Finn, 1989; Gay, 2003; McBee, 2003a, 2003b; Liao et al., 2017; Chopra et al., 2018a; Castro Manrique, 2018). Our study area is located just north of the El Reno Fault and just west of the Nemaha Fault (Figures 1a-b). Seismic imaging (Liao et al., 2017; Chopra et al., 2018a) and analog modelling of these faults (Liao et al., 2017) show strong right-lateral strike-slip kinematics marked by the pervasiveness of NE-trending Reidel splay faults extending outwards from the primary $\sim \mathrm{N}-\mathrm{S}$ principal slip zones. The published seismic images were focused on the shallower and mechanically weaker Woodford Shale unit. Additionally, detailed structural interpretation of a sub-vertical $>12 \mathrm{~km}$-long W- to WNWtrending fault system in Grady County, Oklahoma (south of the study area) suggest leftlateral strike-slip kinematics (Castro Manrique, 2018). Farther east of the study area, published interpretations of the Wilzetta, Whitetail, and the Keokuk Fault zones show mapped secondary faulting patterns and recent focal mechanism solutions consistent with strike-slip kinematics (e.g., McBee, 2003a; McNamara et al., 2015). The consensus is that these fault trends are associated with the major structural deformation of the Anadarko Shelf in a transpressional stress field. The stress field is related to SW- and W-directed compressional stresses from the southward propagation of the Appalachian-OuachitaMarathon fold-thrust belt in the Late Paleozoic (e.g., McBee, 2003a).

(2) The generally small vertical separation $(<100 \mathrm{~m})$ on the large faults (Figures $8 \mathrm{a}-\mathrm{b})$ may imply a relatively larger lateral component of fault slip. However, the maximum Vsep values is not a conclusive evidence since limited coverage of the fault extents by our seismic dataset also makes it difficult to compare with any standard empirical throw-length relationships along faults of known kinematics.

However, the large faults in our study area (F1, F2, F3) are not only in the proximity of these known faults, they also have similar geometries and deform the same stratigraphic units as the structures. Therefore, considering the tectonic history of the Anadarko Shelf and the kinematics of the known faults, we infer that the large faults in focus must have accommodated significant transpressional strain.

\subsubsection{Structural domains of vertical fault propagation}

We analyze three large ( $>10 \mathrm{~km}$-long) through-going faults that extend from the crystalline basement up into the sedimentary cover (faults F1, F2 and F3). These faults do not show any significant growth section in the analyzed interval (Precambrian - Lower Pennsylvanian), suggesting that upward fault propagation into the sedimentary cover is largely postdepositional. The vertical changes in the geometrical character of the deformed stratigraphic surfaces in the seismic cross-sections (e.g., Figures 6c, 7a, 7b), seismic attribute expressions of the fault zone deformation (Figures 6c, S3a-c, S4a-b) suggest that fault deformation is 
propagated up over three distinct structural domains. These domains include: (1) basal block-faulting near (and within) the basement, that transitions through (2) a middle faultedmonocline, into (3) an upper monoclinal flexure (Figure $7 \mathrm{~b}$ ). To better understand the characteristics and drive of upward fault propagation through the deformed sequences, we focus on F1 and F2 as representative large faults and analyze the 3-D distribution of vertical separation (Vsep) along the faults. Overall, we find that Vsep along the large faults generally diminishes toward the intersection zone of the faults (Figure 8a). More importantly, northwards of the intersection zone where significant Vsep is prominent, we assess the trends.

\subsubsection{Vertical Separation versus Depth (Vsep-Z): Vertical fault propagation styles}

The Vsep-Z relationships along the faults describe two broad patterns which we here-in describe as Style-1 and Style-2 (Figures 9a-d). Style- 1 is characterized by a unidirectional, linear decrease of Vsep with shallowing of depth from the Top-Basement surface (Figures 9a and c). Style- 2 is characterized by a bi-directional decrease of Vsep from a deep sedimentary unit (in this case, the Arbuckle carbonates) down toward the basement, and up through the shallower sequences (Figure $9 \mathrm{~b}$ and d). We interpret that Style- 1 involve a basement-driven propagation of faulting, whereas, Style-2 involve an intrasedimentary-driven fault nucleation and propagation.

Along many of the segments with Style-2 Vsep distribution, the faults significantly offset the intrabasement reflectors, but show relatively smaller offset of the Top-Basement and sedimentary cover reflectors (e.g., F1 in Figures 4a; F3 in Figures 5d, 7a). Also, we commonly observe an abrupt change in the dip of the large fault segments across the Top-Basement surface (up to $20^{\circ}$ change; e.g., Figure 7 a). These observations suggest a probable difference in growth history between the basement and sedimentary segments of the large faults. Thus, we interpret that the Style-1 faulting involves a reactivation of pre-existing basement faults. Although Style-2 propagation indicates fault nucleation above the basement, it appears that the pre-existing basement faults help to control where later faults nucleate in the sedimentary cover. Thus, the two styles of vertical fault propagation essentially involve significant or partial reactivation of pre-existing basement faults. Furthermore, the observation of both patterns of fault propagation at different segments of F1 and F2 suggests that the segments of the large fault do not have the same growth history prior to their linkage and coalescence.

These patterns of fault growth may not be unique to contractional or transpressional settings, as they have also been observed in extensional tectonic settings. For example, Collanega et al. (2018) found that normal fault segments that nucleated in the cover rocks show displacement profiles that are clearly distinct from those that physically root into the basement. Of particular interest are the intrasedimentary faults, which show a throw gradient with either the maximum throw at the fault center that decreases towards the tips, or localization of greater throw near the upper tip line than the lower or lateral tips. 


\subsubsection{Efficiency of the vertical fault propagation styles}

To better understand the relative efficiency of vertical propagation of fault deformation by the two propagation styles, we assess the quantitative relationships between Vsep at the nucleation depth levels (Top-Arbuckle and Top-Basement) and one of the shallowest analyzed strata (Top-Chester). For Style-1 propagation, the plot of Top-Basement Vsep (Vsepтв) versus Top-Chester Vsep (Vsертс) shows that $>2.5 \mathrm{~m}$ Vsep is required at TopBasement to propagate deformation as high up as the Mississippian (Figure 10a). In addition, deformation at the Top-Basement could produce about half of its magnitude at depths as shallow as the Mississippian. Similarly, for this same basement-driven fault propagation style, deformation at the Top-Arbuckle will correspond to about half of its magnitude at the Mississippian level (Figure 10b). The plot also shows that only a minimum of $1.7 \mathrm{~m}$ Vsep is needed at the Top-Arbuckle level to propagate deformation up to the Mississippian level. However, when compared to faults that nucleate within the sedimentary cover (Style-2 propagation), deformation at the nucleation zone (Top-Arbuckle) may only produce about a third of its magnitude at the shallow strata (Figure 10b). Furthermore, the plot indicates that a minimum of $\sim 5 \mathrm{~m}$ of Vsep is needed at the nucleation depth (Top-Arbuckle) to propagate deformation as shallow as the Mississippian. These estimates suggest that the basementdriven contractional fault propagation (Style-1) has a relatively greater efficiency of driving deformation to shallower depth levels in the sedimentary cover, compared to intrasedimentary-driven faults.

\subsubsection{Evolution of vertical separation with accrual of fault offset}

Fault F1 has a Vsep max of $96.1 \mathrm{~m}$ suggesting a relatively larger offset fault than fault F2 which has a Vsep max of $30.64 \mathrm{~m}$ (Figures 8a-b). The comparison of the cumulative Vsep versus distance (CVsep-D) plots for the two faults show spatial and systematic clustering of the curves for the analyzed stratigraphic surfaces (Figures S5a-b, 8c-d). Based on the trends shown, we observe that for the larger offset fault F1, most of the shallow strata CVsep-D curves appear to cluster in the region between the $0.25 \cdot \mathrm{CV}^{2} \mathrm{p}_{\max }$ and $0.75 \cdot \mathrm{CV} \mathrm{Sp}_{\max }$ boundaries (Figure 8c, S5a). Whereas, for the smaller offset fault F2, most of the shallow strata CVsep-D curves cluster within or just above the region below the $0.25 \cdot \mathrm{CV} \mathrm{sep}_{\max }$ boundary (Figures $8 \mathrm{~d}, \mathrm{~S} 5 \mathrm{~b}$ ). This is reasonable considering that with increase fault growth and upward propagation of the fault tip, more of the initially monoclinally-folded strata at shallower depths become faulted. The spacing of these curves may also indicate the relative intensity of strain accommodated by different faulted-monocline strata (same CVsep-D region), as well as between units that have accommodated only folding and those that have experienced both faulting and folding. Therefore, we infer that with increasing accrual of offset on these faults, more of the shallow strata CVsep-D curves transition from lower value regions $(<0.25 \cdot$ CVsepmax $)$ into the moderate and higher value regions. Thus, we present a 
simplified conceptual model of evolution of CVsep-D trends that vary with accrual of offset along basement-rooted contractional and transpressional faults (Figure 11a-c).

\subsection{Implications for the structural inheritance and subsurface fluid migration}

The geometry and shallow reaches of the deformation of the large faults our study area pose important significance for (1) basement-sedimentary and intrasedimentary fluid transport, and (2) modern seismic hazard in the Anadarko Shelf. The observations presented here demonstrate that only the brittle component of the intrabasement deformation is inherited by the sedimentary sequences. Thus, the fault connectivity presents potential pathways for migration of basement-derived hydrothermal fluids into the sedimentary cover, source to reservoir migration of hydrocarbons, and downward migration of fluids from the cover rocks into the basement. This is supported by recent observations of hydrothermal alteration of carbonate reservoirs in the Anadarko Shelf (e.g., Mohammadi et al., 2017; Jaiswal et al., 2017). In other basins where basement-rooted transpressional faults exist, near-fault diagenetic hydrothermal alterations can localize "light-bulb" structures and influence the local petroleum system and metallic-ore mineralization trends (e.g., the Appalachian foreland basins of Eastern US, Evenick, 2006; Evenick \& Hatcher, 2006; Smith Jr \& Davies, 2006). Further, the structural inheritance of basement fault systems by the sedimentary sequences may explain the recent widespread seismogenic strike-slip reactivation in north-central Oklahoma, attributed to sedimentary-to-basement migration of fluids (e.g., Qin et al., 2018, 2019; Kolawole et al., 2019b).

Finally, on the timing of upward propagation of the inherited structures, based on the lack of significant growth strata along the analyzed faults, the post-Cambrian ages of the gentlydipping shelf sequences, and analyses of the character of the basement faults, we infer a Late Paleozoic age. We summarize the history of structural deformation of the Anadarko Shelf as follows (Figure 11d): Stage 1: development of steep basement faults associated with the southward propagation of the Mid-Continent Rift in the Precambrian; Stage 2: Erosion of the Top-Basement and deposition of sedimentary sequences in the Early to Mid-Paleozoic; and Stage 3: Late Paleozoic transpressional reactivation and upward propagation of the basement faults, leading to the folding and faulting of the cover rocks. We suggest that the systematic 3-D characterization of the distribution of deformation along basement-rooted transpressional faults, as presented in this study, could help provide more insight into the mechanics of inherited fault propagation in contractional tectonic settings.

\section{CONCLUSIONS}

Here, we characterized the intrabasement structure of the Precambrian basement of the Anadarko Shelf, Oklahoma and investigated how the brittle component of the basement structure is inherited by the overlying sedimentary sequences. Our study revealed pervasive deformation of the granitic basement by two major structures: (a.) basement-bounded mafic 
sills, and (b.) sub-vertical discontinuity planes interpreted as faults, some of which penetrate the overlying sedimentary cover. Overall, based on our dataset, we inferred that at least the brittle component of the intrabasement deformation was inherited by the sedimentary sequences of the Anadarko Shelf. We found that deformation along the basement fault is propagated up the cover over three structural domains: 1) basal faulted-block, 2) middle faulted-monocline that transitions into 3) monoclinal flexure. Our analyses revealed two styles of Vertical Separation - Depth relationships which include a basement-driven unidirectional propagation (Style-1), and an intrasedimentary-driven fault nucleation and bi-directional propagation (Style-2). Further, we showed that along-fault deformation of affected stratigraphic surfaces exhibits systematic trends that varies with offset accrual. Furthermore, we demonstrated that the basement-driven fault propagation has greater efficiency of propagating the fault-related deformation to shallower depths compared to the intrasedimentary-driven nucleation and propagation. Finally, we suggested that the through-going basement-rooted faults in the study area are likely Proterozoic and were later reactivated in transpression in the Late Paleozoic.

Using geophysical and geological data, we present one of the first results showing ground truthing evidence of the composition of the widely observed intrabasement seismic reflectors (IBRS) in the Mesoproterozoic Granite-Rhyolite Province of central-eastern US. Our study suggests that the IBRs are basement-bounded mafic sill intrusions. The Anadarko Shelf deformation represents only a partial inheritance of the observed heterogeneous intrabasement deformation by the sedimentary cover. The systematic characterization of basement deformation and its propagation as presented in this study provide an increased understanding of the mechanics of structural inheritance in contractional tectonic settings.

\section{ACKNOWLEDGEMENTS}

Thanks to TGS for providing access to the 3-D Seismic Reflection and well data used in this study. We thank Chesapeake Energy Corporation, Oklahoma City for providing access to the computer software and hardware used to analyze and interpret the seismic data. We thank the Oklahoma Petroleum Information Center (OPIC), Norman, OK for providing access to the basement penetration borehole drill cuttings used in this study. Also, we thank the Chesapeake Energy Reservoir Technology Center for the photographs, X-ray diffraction and $\mathrm{X}$-ray fluorescence analyses of the drill cuttings. We thank Laura Bellingar for assistance with basement well log synthetic modelling, Matthew Davis for assistance with the phase assessment of the seismic dataset, and Michael Horn for assistance with the seismic attribute computation. We also thank the Editor Craig Magee, and reviewers Rebecca E. Bell and Alexander Peace for their constructive feedback.

Data Availability Statement: The 3-D seismic dataset that support the findings of this study are available on request from TGS (global.marketing@tgs.com). The vertical separation and 
geochemical data (XRD and XRF) that support the findings of this work are available as supplementary files of this manuscript.

\section{REFERENCES}

Anderson, H., Ellis, J. F., Muir, R., \& Macaulay, E. (2015). September. 3-D Trishear: Parameters and Possibilities. AAPG-SEG International Conference and Exhibition, Melbourne, Australia 1316 September 2015 (525-525).

Benson, W. A. (2014). The Spavinaw Granite (Proterozoic), Mayes County, Oklahoma. The Shale Shaker, 65, 258-264.

Berg, R. R. (1962). Mountain flank thrusting in Rocky Mountain foreland, Wyoming and Colorado. AAPG Bulletin, 46, 2019-2032.

Brewer, J. A., Good, R., Oliver, J. E., Brown, L. D., \& Kaufman, S. (1983). COCORP profiling across the Southern Oklahoma aulacogen: Overthrusting of the Wichita Mountains and compression within the Anadarko Basin. Geology, 11, 109-114.

Brown, W. G. (1983). Sequential development of the fold-thrust model of foreland deformation, In Lowell, J. D. ed., Rocky Mountain foreland basins and uplifts, Denver, Colorado. Rocky Mountain Association of Geologists, 57-64.

Burberry, C. M. (2015). Spatial and temporal variation in penetrative strain during compression: insights from analog models. Lithosphere, 7, 611-624.

Burberry, C. M. (2016). Penetrative Strain on the Field Scale: Detrimental to Reservoir Quality? AAPG Annual Convention and Exhibition 2016, Search and Discovery Article \#51300.

Burberry, C. M., \& Lowe, J. B. (2019). Analog Modeling of Penetrative Strain Around Laramide Structures: Similarities and Differences Between Thick and Thin-Skinned Styles of Deformation. AAPG Annual Convention and Exhibition 2018, poster \# 420-P55.

Cannon, W. F. (1994). Closing of the Midcontinent rift - A far-field effect of Grenvillian compression. Geology, 22, 155-158.

Castro Manrique, B. J. (2018). Structural Geology of the Woodford Shale in the Southeastern Anadarko Basin, Grady County, Oklahoma. MS Thesis, University of Oklahoma, Norman.

Chase, B., Atekwana, E. A., Kolawole, F., Turko, M. S., Carpenter, B. M., Evans, R. L. \& Finn, C. (2018). December. The Southern Oklahoma Aulacogen: New Insights from Aeromagnetic, Seismic Reflection and Magnetotelluric Data Analyses. In AGU Fall Meeting Abstract \#G51E0523. 
Chopra, S., \& Marfurt, K. (2006). Seismic Attributes-a promising aid for geologic prediction. CSEG Recorder, 31, 110-120.

Chopra, S., \& Marfurt, K. J. (2005). Seismic attributes - A historical perspective. Geophysics, 70, 3SO-28SO.

Chopra, S., Marfurt, K., Kolawole, F., \& Carpenter, B. M. (2018a) Nemaha Strike-Slip Fault Expression on 3-D Seismic Data in SCOOP Trend. AAPG Explorer, Search and Discovery Article \#42235.

Chopra, S., Infante-Paez, L., \& Marfurt, K. J. (2018b). Intra-Basement Intrusions in the STACK Area of Oklahoma. AAPG Geophysical Corner, AAPG Search and Discovery \#42229.

Collanega, L., Suida, K., Jackson, C. A.-L., Bell, R. E., Coleman, A. J., Lenhart, A., Magee, C., \& Breda, A. (2019). Normal fault growth influenced by basement fabrics: the importance of preferential nucleation from pre-existing structures. Basin Research, 31, 659-687.

Coward, M. P. (1983). Thrust tectonics, thin skinned or thick skinned, and the continuation of thrusts to deep in the crust. Journal of Structural Geology, 5, 113-123.

Denison, R. E. (1981). Basement rocks in northeastern Oklahoma. Oklahoma Geological Survey Circular 84. Norman, OK.

Denison, R. E. (1995). Significance of air-photograph linears in the basement rocks of the Arbuckle Mountains. Oklahoma Geological Survey Circular 97, 119-131.

Denison, R. E., Bickford, M. E., Lidiak, E. G., \& Kisvarsanyi, E. B. (1987). Geology and geochronology of Precambrian rocks in the central interior region of the United States. U.S. Geological Survey Professional Paper 1241-C.

Dolton, G. L., \& Finn, T. F. (1989). Petroleum geology of the Nemaha uplift, central midcontinent. Dept. of the Interior, US Geological Survey, No. 88-450-D.

Droege, L., \& Vick, H. (2018). Redefining the STACK Play from Subsurface to Commercialization: Identifying Stacked Pay Sweet Spots in the Northern Anadarko Basin. AAPG ACE 2018 Annual Convention \& Exhibition, Salt Lake City, Utah. Search and Discovery Article \#11104.

Elebiju, 0. O., Matson, S., Keller, G. R., \& Marfurt, K. J. (2011). Integrated geophysical studies of the basement structures, the Mississippi chert, and the Arbuckle Group of Osage County region, Oklahoma. AAPG Bulletin, 95, 371-393.

Erslev, E. A., \& Koenig, N. V. (2009). Three-dimensional kinematics of Laramide, basementinvolved Rocky Mountain deformation, USA: Insights from minor faults and GIS-enhanced structure maps. Geological Society of America Memoirs, 204, 125-150.

Evenick, J. C., 2006, Potential subsurface structures and hydrocarbon reservoirs in the southern Appalachian basin beneath the Cumberland Plateau and eastern Highland Rim, 
Tennessee, Kentucky, and southwestern Virginia. University of Tennessee, Ph.D. Dissertation, 402.

Evenick, J. C., \& Hatcher, R. D. Jr. (2006). Trenton-Black River suggested as common nomenclature across Appalachian basin. Oil and Gas Journal, 104, 31-36.

Font, R. G. (2003). Layered basement, basement truncated wedges, structural patterns, tectonic evolution, and seismic expression of Montague County, West of Muenster Arch in North Texas, USA. The Professional Geologist, 40, 2-7.

Frohlich, C., DeShon, H., Stump, B., Hayward, C., Hornbach, M., \& Walter, J. I. (2016). A historical review of induced earthquakes in Texas. Seismological Research Letters, 87, 10221038.

Gay Jr, S. P. (2003). The Nemaha Trend-a System of Compressional Thrust-Fold, Strike-Slip Structural Features in Kansas and Oklahoma, (Part 2, Conclusion). The Shale Shaker, 54, 3949.

Gay Jr., S. P. (1999), Strike-slip, compression thrust-fold nature of the Nemaha system in eastern Kansas and Oklahoma, in D.F. Merrian (ed.) Transactions of the 1999 AAPG Midcontinent section meeting: Kansas Geol. Surv. Open File Rep., 99-28.

Gwon, S., \& Kim, Y. S. (2016). Interpretation of deformation history and paleostress based on fracture analysis exposed in a trench. The Journal of Engineering Geology, 26, 33-49.

Hardy, S., \& Ford, M. (1997). Numerical modeling of trishear fault propagation folding. Tectonics, 16, $841-854$.

Hardy, S., \& Allmendinger, R. W. (2011). Trishear: A review of kinematics, mechanics, and applications, in McClay, K., Shaw, J., \& Suppe, J., eds., Thrust fault-related folding. AAPG Memoir 94, 95-119.

Harper, T., Fossen, H., \& Hesthammer, J. (2001). Influence of uniform basement extension on faulting in cover sediments. Journal of Structural Geology, 23, 593-600.

Henry, M. E., \& Hester, T. C. (1995). Anadarko basin province (058), in Gautier, D. L., Dolton, G. L., Takahashi, K. I., and Varnes, K. L., ed., 1995 National assessment of United States oil and gas resources--Results, methodology, and supporting data: U.S. Geological Survey Digital Data Series DDS-30, Release 2.

Iaffa, D. N., Sàbat, F., Muñoz, J. A., Mon, R., \& Gutierrez, A. A. (2011). The role of inherited structures in a foreland basin evolution. The Metán Basin in NW Argentina. Journal of Structural Geology, 33, 1816-1828.

Infante-Paez, L., \& Marfurt, K. J. (2017). Seismic expression and geomorphology of igneous bodies: A Taranaki Basin, New Zealand, case study. Interpretation, 5, SK121-SK140. 
Jaiswal, P., Gregg, J. M., Parks, S., Holman, R., Mohammadi, S., \& Grammer, G. M. (2017). Evidence of fault/fracture "Hydrothermal" reservoirs in the southern midcontinent Mississippian carbonates. In Grammer, G. M., Gregg, J. M., Puckette, J. O., Jaiswal, P., Mazzullo, S. J., Pranter, M. J., \& Goldstein, R. H., eds., Mississippian Reservoirs of the Midcontinent. $A A P G$ Memoir 116.

Johnson, K. S. (1989). Geologic evolution of the Anadarko basin. Oklahoma Geological Survey Circular, 90, 3-12.

Johnson, K. S. (2008). Geologic history of Oklahoma. Earth sciences and mineral resources of Oklahoma. Oklahoma Geological Survey Educational Publication, 9, 3-5.

Keller, G. R., \& Stephenson, R. A. (2007) The Southern Oklahoma and Dniepr-Donets aulacogens: A comparative analysis, in Hatcher, R. D., Jr., Carlson, M. P., McBride, J. H., \& Martínez Catalán, J. R., eds., 4-D Framework of Continental Crust. Geological Society of America Memoir, 200, 127-143.

Kibikas, W.M., Carpenter, B. M., \& Ghassemi, A. (2019) The Petrophysical and Mechanical Properties of Oklahoma's Crystalline Basement. In 53rd US Rock Mechanics/Geomechanics Symposium, American Rock Mechanics Association, August 2019.

Kim, D., \& Brown, L.D. (2019). From trash to treasure: Three-dimensional basement imaging with "excess" data from oil and gas explorations. AAPG Bulletin, 103, 1691-1701.

Kolawole, F., Atekwana, E. A., Laó-Dávila, D. A., Abdelsalam, M. G., Chindandali, P. R., Salima, J., \& Kalindekafe, L. (2018). Active deformation of Malawi rift's north basin Hinge zone modulated by reactivation of preexisting Precambrian Shear zone fabric. Tectonics, 37, 683704.

Kolawole, F., Phillips, T. B., Atekwana, E. A., Jackson, C. A-L (2019a). Structural Inheritance Controls Strain Distribution During Early Continental Rifting, Rukwa Rift. EGU General Assembly Conference Abstract EGU2019-1849 (vol. 21).

Kolawole, F., Johnston, C. S., Morgan, C. B., Chang, J. C., Marfurt, K. J., Lockner, D. A., Reches, Z. \& Carpenter, B. M. (2019b). The susceptibility of Oklahoma's basement to seismic reactivation. Nature Geoscience, 12, 839-844.

Lacombe, O., \& Bellahsen, N. (2016). Thick-skinned tectonics and basement-involved foldthrust belts: insights from selected Cenozoic orogens. Geological Magazine, 153, 763-810.

Lee, J., \& Kim, Y. S. (2018). Deformation history based on the characteristics of dikecontrolled faults and cross-cutting relationship between dikes and faults. In AGU Fall Meeting Abstracts \#T23A-0326.

Liao, Z., Liu, H., Jiang, Z., Marfurt, K. J., \& Reches, Z. E. (2017). Fault damage zone at subsurface: A case study using 3D seismic attributes and a clay model analog for the Anadarko Basin, Oklahoma. Interpretation, 5, T143-T150. 
Lidiak, E. G., Denison, R. E., \& Stern, R. J. (2014). Cambrian (?) Mill Creek Diabase Dike Swarm, Eastern Arbuckles: A Glimpse of Cambrian Rifting in the Southern Oklahoma Aulacogen. Oklahoma Geological Survey Guidebook 38, 105-122.

Lihou, J. C., \& Allen, P. A. (1996). Importance of inherited rift margin structures in the early North Alpine Foreland Basin, Switzerland. Basin Research, 8, 425-442.

Lowell, J. D. (1995). Mechanics of basin inversion from worldwide examples. Geological Society, London, Special Publications, 88, 39-57.

Marsh, S. \& Holland, A. (2016). Comprehensive fault database and interpretive fault map of Oklahoma. Oklahoma Geol. Survey Open-File Report, 15.

McBee, W. (2003a). The Nemaha and other strike-slip faults in the midcontinent USA. AAPG Mid-Continent Section Meeting Proceedings, Tulsa, OK., 1-23.

McBee, W. (2003b). Nemaha strike-slip fault zone, paper presented at AAPG Mid-continent section meeting, Oct. 13.

McBride, J. H., Leetaru, H. E., Keach, R. W., \& McBride, E. I. (2016). Fine-scale structure of the Precambrian beneath the Illinois Basin. Geosphere, 12, 585-606.

McBride, J. H., William Keach II, R., Leetaru, H. E., \& Smith, K. M. (2018). Visualizing Precambrian basement tectonics beneath a carbon capture and storage site, Illinois Basin. Interpretation, 6, T257-T270.

McClay, K. (2011). Introduction to thrust fault-related folding, in McClay, K., Shaw, J., \& Suppe, J., eds., Thrust fault-related folding. AAPG Memoir 94, 1-19.

McClay, K. R., \& Ellis, P. G. (1987). Geometries of extensional fault systems developed in model experiments. Geology, 15, 341-344.

McNamara, D. E., Rubinstein, J. L., Myers, E., Smoczyk, G., Benz, H. M., Williams, R. A., Hayes, G., Wilson, D., Herrmann, R., McMahon, N. D., \& Aster, R. C. (2015). Efforts to monitor and characterize the recent increasing seismicity in central Oklahoma. The Leading Edge, 34, 628639.

Mitra, S., \& Mount, V. S. (1998). Foreland basement-involved structures. AAPG bulletin, 82, 70-109.

Mohammadi, S., Gregg, J. M., Shelton, K. L., Appold, M. S., \& Puckette, J. O. (2017). Influence of late diagenetic fluids on Mississippian carbonate rocks on the Cherokee-Ozark Platform, NE Oklahoma, NW Arkansas, SW Missouri, and SE Kansas. In Grammer, G. M., Gregg, J. M., Puckette, J. O., Jaiswal, P., Mazzullo, S. J., Pranter, M. J., \& Goldstein, R. H., eds., Mississippian Reservoirs of the Midcontinent. AAPG Memoir 116.

Reeve, M. T., Bell, R. E., Jackson, C. A. L. (2014). Origin and significance of intra-basement seismic reflections offshore western Norway. Journal of the Geological Society, 171, 1-4. 
Naylor, M. A., Mandl, G. T., \& Supesteijn, C. H. K. (1986). Fault geometries in basementinduced wrench faulting under different initial stress states. Journal of Structural Geology, 8 , 737-752.

Phillips, T. B., Magee, C., Jackson, C. A. L., \& Bell, R. E. (2018). Determining the threedimensional geometry of a dike swarm and its impact on later rift geometry using seismic reflection data. Geology, 46, 119-122.

Powers, S. (1928). Age of the Folding of the Oklahoma Mountains-the Ouachita, Arbuckle, and Wichita Mountains of Oklahoma and the Llano-Burnet and Marathon Uplifts of Texas. Bulletin of the Geological Society of America, 39, 1031-1071.

Prucha, J. J., Graham, J. A., \& Nickelson, R. P. (1965). Basement controlled deformation in Wyoming province of Rocky Mountain foreland. AAPG Bulletin, 49, 966-992.

Qin, Y., Chen, X., Carpenter, B. M., \& Kolawole, F. (2018). Coulomb stress transfer influences fault reactivation in areas of wastewater injection. Geophysical Research Letters, 45, 11-059.

Qin, Y., Chen, X., Walter, J. I., Haffener, J., Trugman, D. T., Carpenter, B. M., Weingarten, M., \& Kolawole, F. (2019). Deciphering the stress state of seismogenic faults in Oklahoma and southern Kansas based on an improved stress map. Journal of Geophysical Research: Solid Earth, 124.

Ramsay, J. G. (1967). Folding and fracturing of rocks. Mc Graw Hill Book Company, 568.

Ramsay, J. G., \& Huber, M. I. (1987). The techniques of modern structural geology: Folds and fractures, volume 2. Academic Press.

Reches, Z. E. (1978), Development of monoclines: Part I. Structure of the Palisades Creek branch of the East Kaibab monocline, Grand Canyon, Arizona. Laramide folding associated with basement block faulting in the western United States. Geol. Soc. Amer. Mem., 151, 235271.

Shah, A. K., \& Keller, G. R. (2017). Geologic influence on induced seismicity: Constraints from potential field data in Oklahoma. Geophysical Research Letters, 44, 152-161.

Simpson, M. (2015) A Structural Re-Evaluation of the Ardmore Basin. In Mid-Continent Section. Search and Discovery Article \#10795. AAPG Mid-Continent Section meeting in Tulsa, Oklahoma, October 4-6, 2015.

Schoenball, M., \& Ellsworth, W. L. (2017). Waveform-relocated earthquake catalog for Oklahoma and southern Kansas illuminates the regional fault network. Seismological Research Letters, 88, 1252-1258.

Smith Jr, L. B., \& Davies, G. R. (2006). Structurally controlled hydrothermal alteration of carbonate reservoirs: Introduction. AAPG Bulletin, 90, 1635-1640. 
Stearns, D. W., 1975, Laramide basement deformation in the Bighorn basin-the controlling factor for structures in the layered rocks. Geology and mineral resources of the Bighorn basin, Wyoming. Geological Association 27th Annual Field Conference Guidebook, 149-158.

Stearns, D. W., 1978, Faulting and forced folding in the Rocky Mountain foreland, in V. Matthews III, ed., Laramide folding associated with basement block faulting in the western United States. Geological Society of America Memoir 151, 1-37.

Stein, S., Stein, C. A., Elling, R., Kley, J., Keller, R., Wysession, M., Rooney, T., Frederiksen, A., \& Moucha, R. (2018). Insights from North America's failed Midcontinent Rift into the evolution of continental rifts and passive continental margins. Tectonophysics.

Stone, D. S. (1993). Basement-involved thrust-generated folds as seismically imaged in the subsurface of the central Rocky Mountain foreland, In Schmidt, C. J., Chase, R. B., \& Erslev, E. A. eds., Laramide basement deformation in the Rocky Mountain foreland of the western United States. Geological Society of America Special Paper 280, 271-318.

Subrahmanyam, D., \& Rao, P. H. (2008). Seismic attributes-A review. In 7th International Conference \& Exposition on Petroleum Geophysics, Hyderabad, 398-404.

Suppe, J. (1983). Geometry and kinematics of fault-bend folding. American Journal of Science, 283, 684-721.

Thomas, J. J., Shuster, R. D., \& Bickford, M. E. (1984). A terrane of 1,350-to 1,400-my-old silicic volcanic and plutonic rocks in the buried Proterozoic of the mid-continent and in the Wet Mountains, Colorado. Geological Society of America Bulletin, 95, 1150-1157.

Tindall, S.E., and Davis. G.H. 1999. Monocline development by oblique-slip fault-propagation folding: The East Kaibab monocline, Colorado Plateau, Utah. Journal of Structural Geology, 21, 1303-1320.

Turner, J. P., \& Williams, G. A. (2004). Sedimentary basin inversion and intra-plate shortening. Earth-Science Reviews, 65, 277-304.

Van der Pluijm, B. A., \& Catacosinos, P. A. (1996). Basement and basins of eastern North America. Geological Society of America Special Paper, 308.

Van Schmus, W. R., \& Hinze, W. J. (1985). The midcontinent rift system. Annual Review of Earth and Planetary Sciences, 13, 345-383.

Wall, M., Cartwright, J., Davies, R., \& McGrandle, A. (2010). 3D seismic imaging of a Tertiary Dyke Swarm in the Southern North Sea, UK. Basin Research, 22, 181-194.

Whitmeyer, S. J., \& Karlstrom, K. E. (2007). Tectonic model for the Proterozoic growth of North America. Geosphere, 3, 220-259.

Widess, M. B., \& Taylor, G. L. (1959). Seismic reflections from layering within the preCambrian basement complex, Oklahoma. Geophysics, 24, 417-425. 
Yee, D., Johnston, G., Howard, D. and Ahmed, S., 2017, September. STACKing It Up: An Economic and Geological Analysis of the STACK. In Unconventional Resources Technology Conference, Austin, Texas, 24-26 July 2017, 2496-2501. Society of Exploration Geophysicists, American Association of Petroleum Geologists, Society of Petroleum Engineers.

Yonkee, W. A. (1992). Basement-cover relations, Sevier orogenic belt, northern Utah. Geological Society of America Bulletin, 104, 280-302.

Zaleski, E., Eaton, D. W., Milkereit, B., Roberts, B., Salisbury, M., \& Petrie, L., (1997). Seismic reflections from subvertical diabase dikes in an Archean terrane. Geology, 25, 707-710. 
(a)

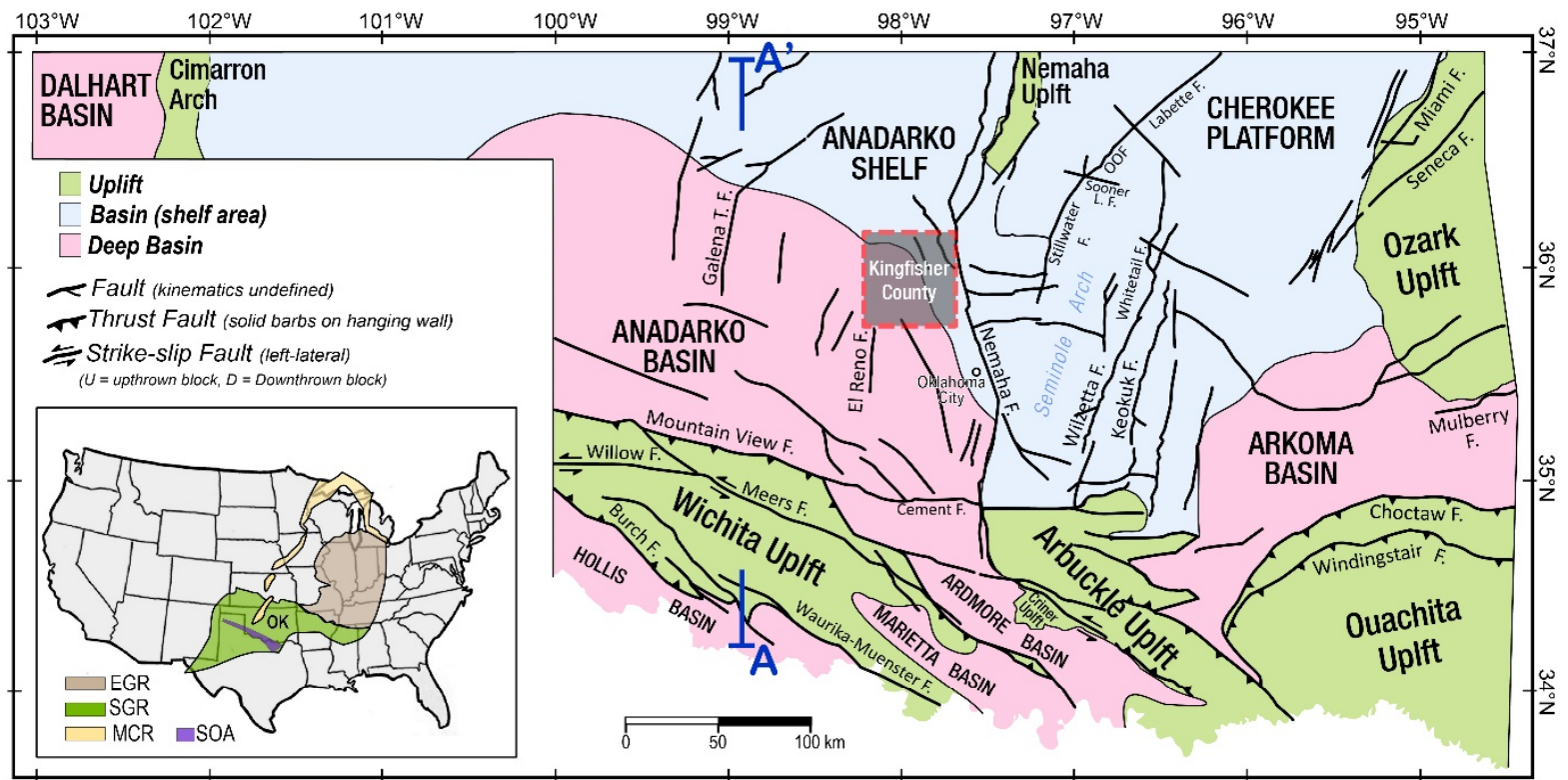

(b)

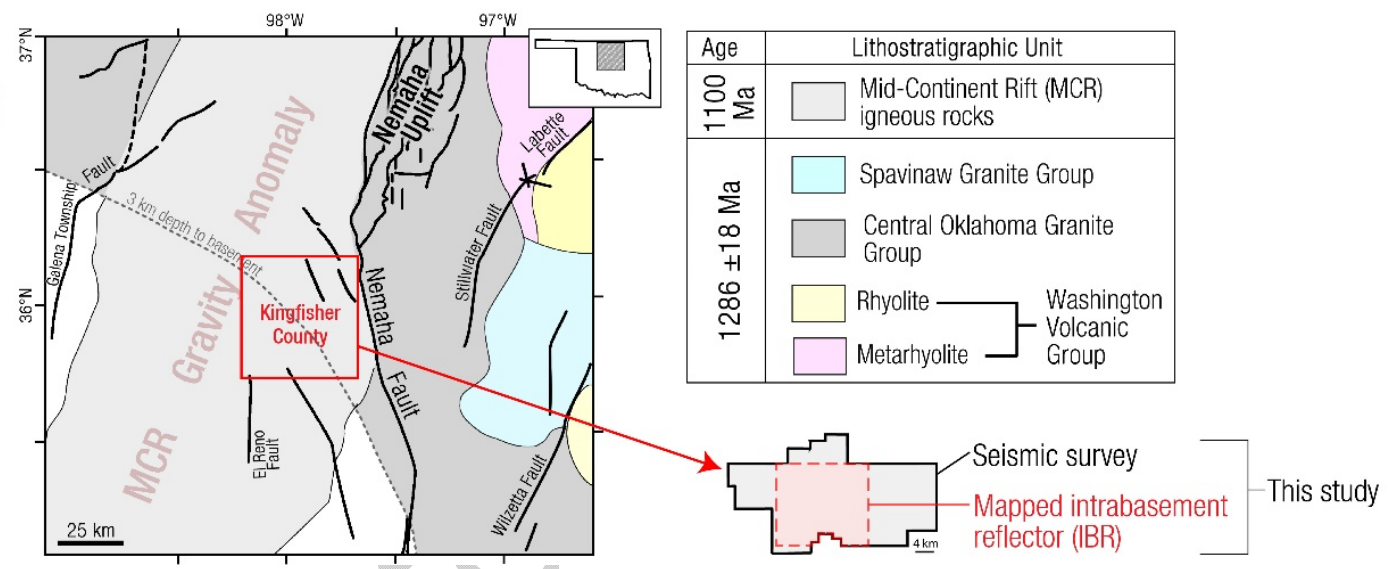

FIGURE 1 (a) Map of Oklahoma, showing the location of the study area (red dashed square), geologic provinces (after Northcutt and Campbell, 1995), and major faults (Marsh and Holland, 2016; Chase et al., 2018) area. Inset: Map showing the Precambrian igneous basement terranes in the central and eastern United States (after Thomas et al., 1984; Bickford et al., 2015). EGR = Eastern GraniteRhyolite Province (1440-1480 Ma); SGR = Southern Granite-Rhyolite Province (1350-1400 Ma); MCR = Mid-Continent Rift $(\sim 1100 \mathrm{Ma})$; SOA = Southern Oklahoma Aulacogen $(\sim 520 \mathrm{Ma})$; OK = Oklahoma. (b) Basement geology of north-central Oklahoma (after Denison, 1966, 1981; Shah \& Keller, 2016; Stein et al., 2018). Red arrow points to the outline of the 3D seismic survey used in this study. 

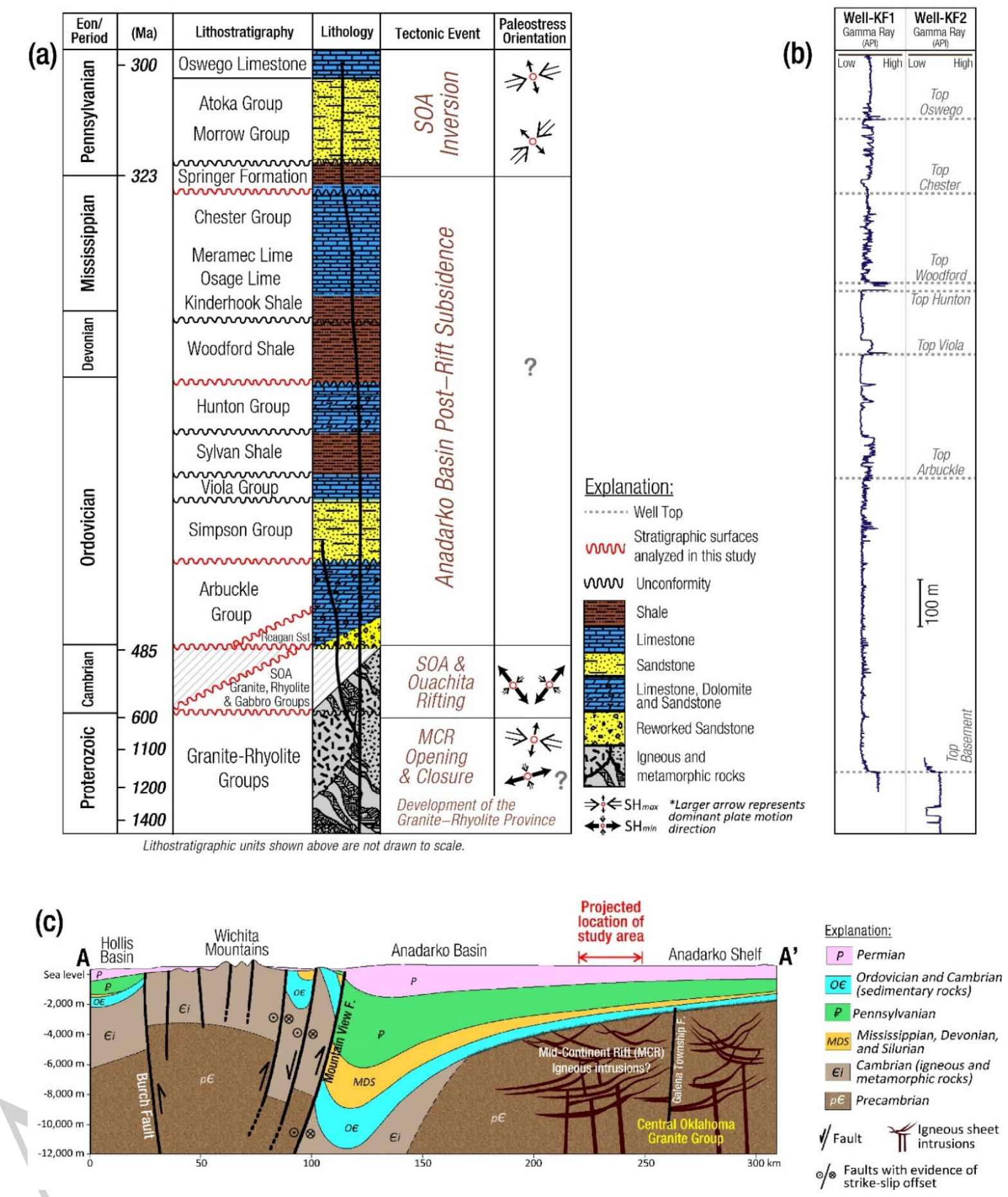

FIGURE 2 (a) Generalized stratigraphic column of the Anadarko Basin, Oklahoma (after Henry \& Hester, 1995; Elebiju et al., 2011). (b) Gamma Ray logs and associated stratigraphic tops for two basement penetration well-KF1 and -KF2 within the study area. We used Well-KF1 for our seismicwell tie. See Figures 3 and S2 for more details on Well-KF2 (additional logs, drill cuttings, and geochemical analysis). (c) Cross-section A-A' (transect in Figure 1A) across the Anadarko Basin, Oklahoma, showing the subsurface configuration of the basin, associated stratigraphic units and 
basement features (after Brewer et al., 1983; Johnson, 2008; Simpson, 2015). The section also shows the projected location of the study area.

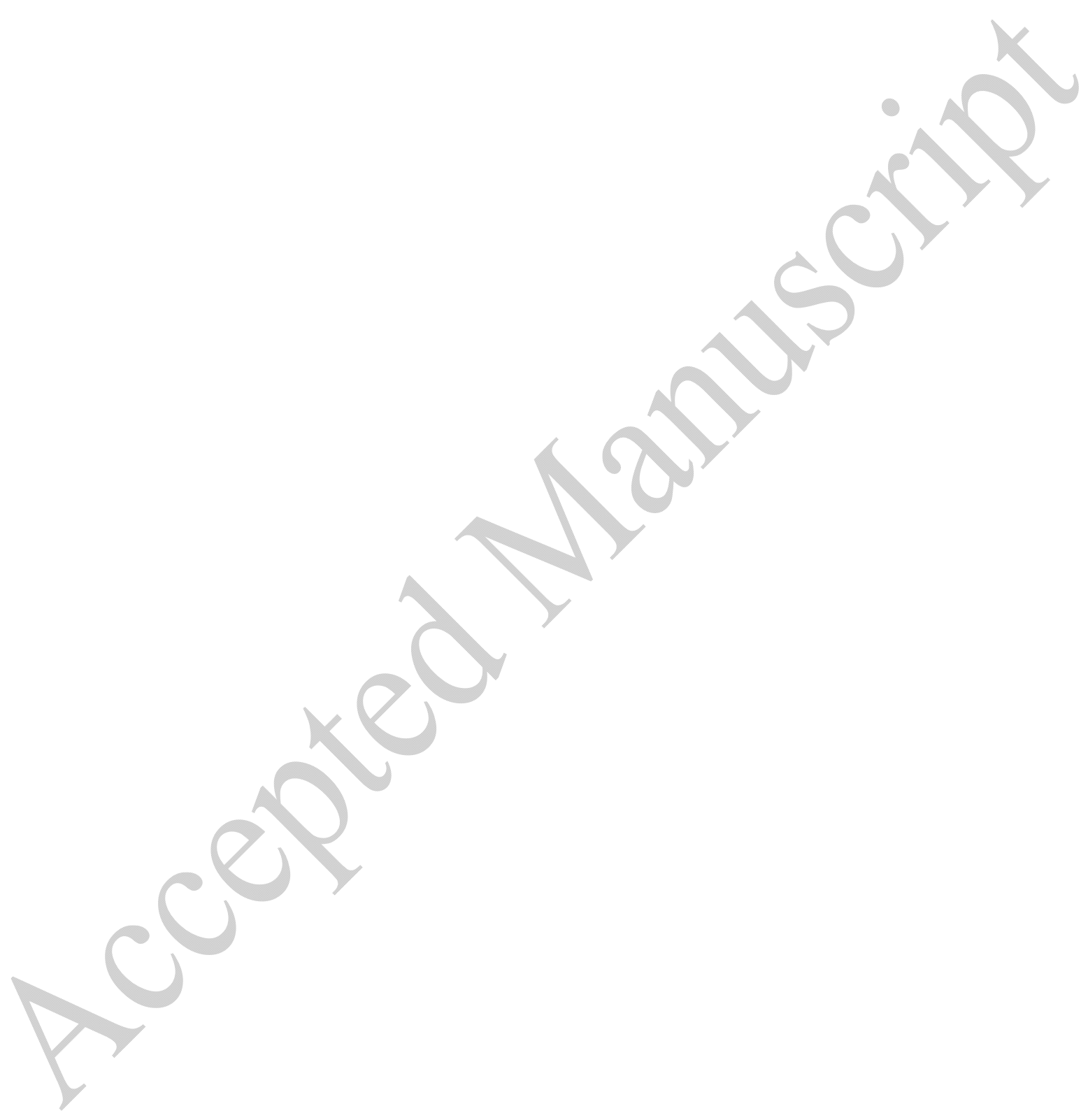




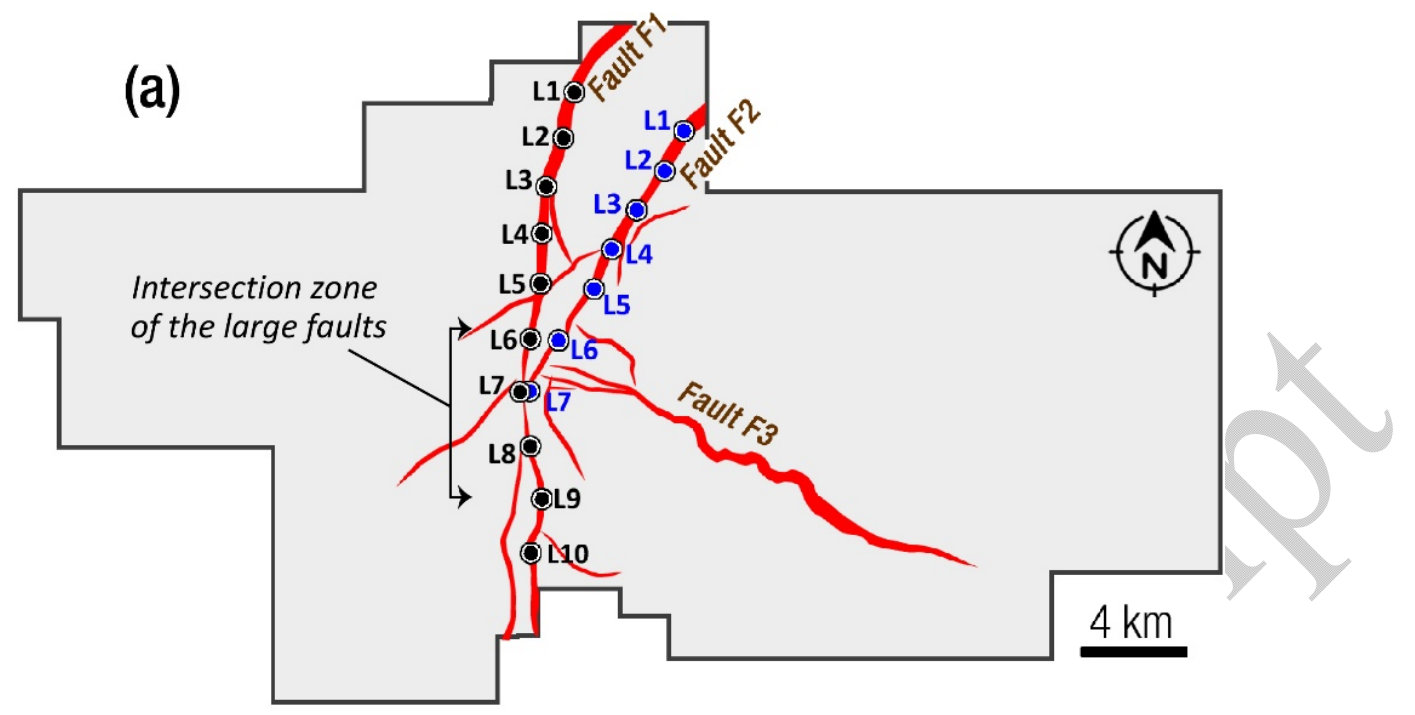

(b)

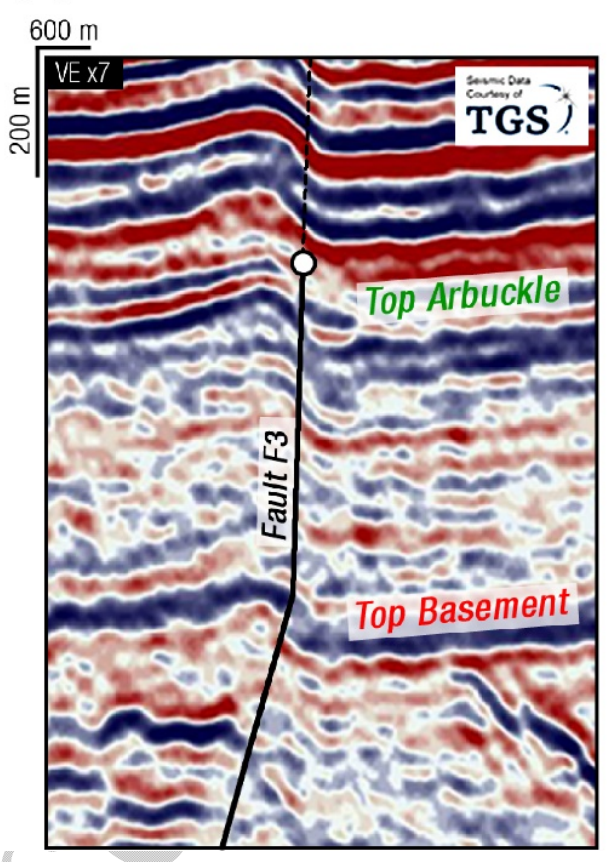

(c)

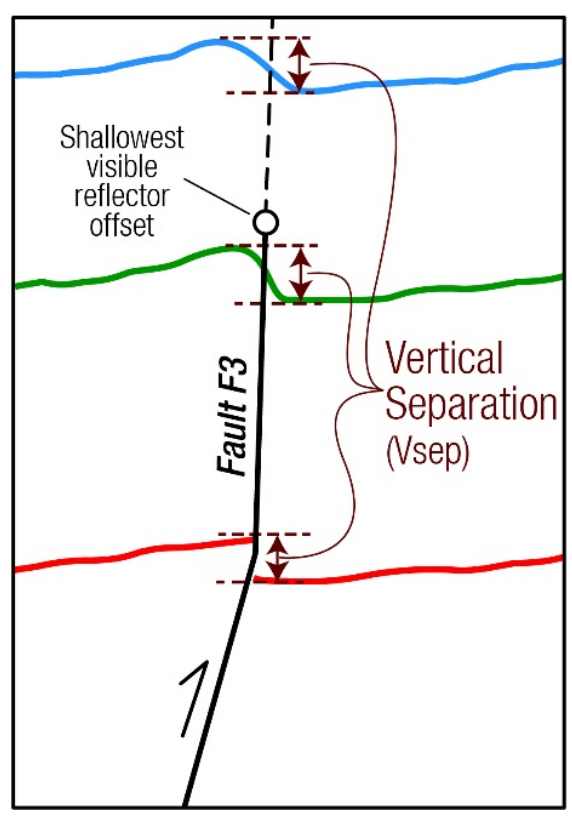

FIGURE 3 (a) A map of the seismic survey showing the large faults in the study area, and the $2 \mathrm{~km}$ interval locations at which vertical separation (Vsep) measurements were obtained (L1-L10 along F1; L1-L7 along F2). (b) Representative seismic section and (c) interpretation illustrating how the Vsep measurements were obtained at each of the locations. 

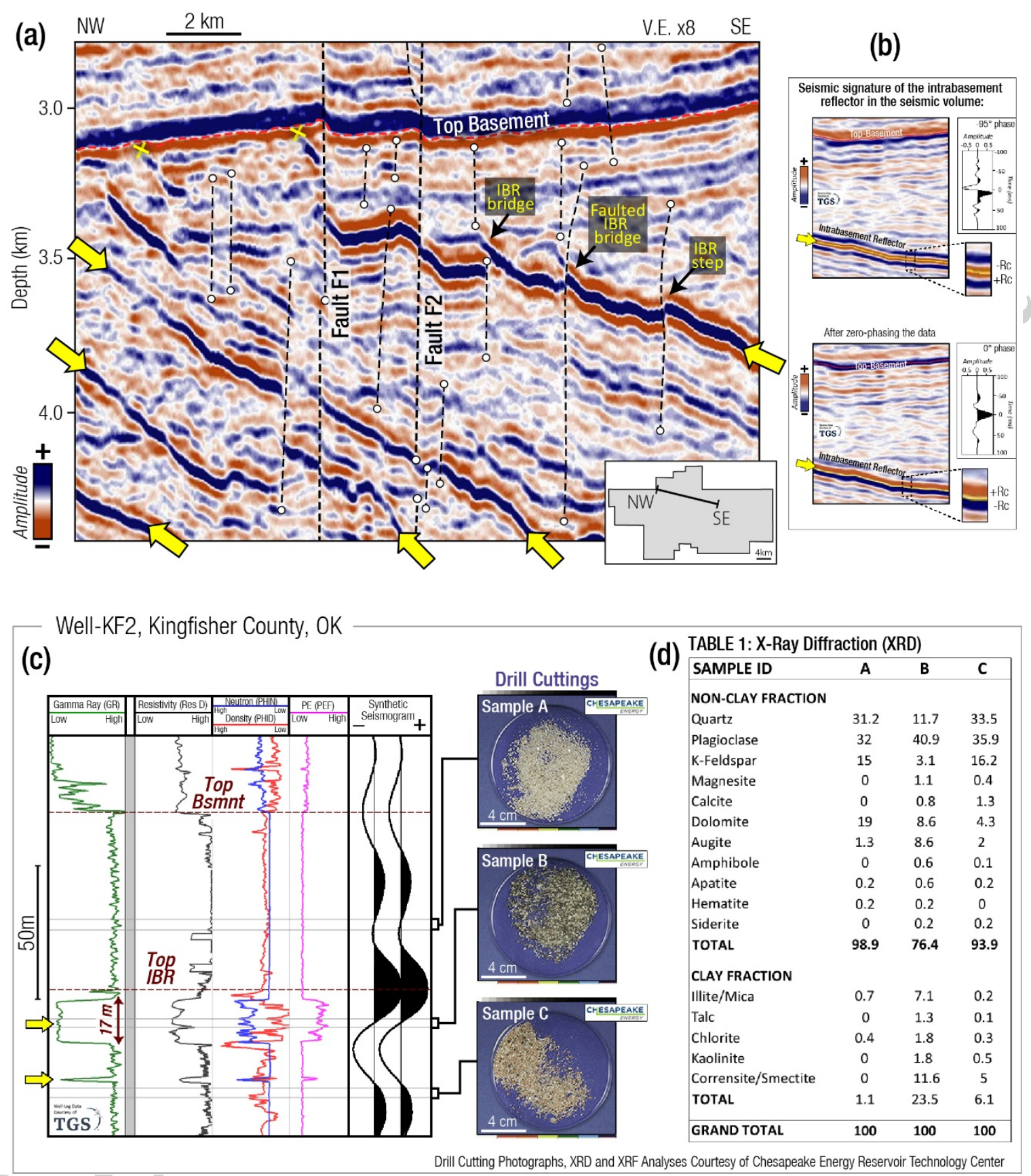

FIGURE 4 (a) Representative cross-section through the 3-D seismic dataset used in this study (transect in the bottom-right corner) showing distinct patterns of the intrabasement reflectors (IBR) in the area (yellow arrows) and geometry of interacting segments. The yellow "X-symbols" indicate the shallowest reaches of the IBRs terminating at the basement-sedimentary interface. Data courtesy of TGS. (b) Top: Representative seismic section and wavelet from the interpreted volume showing that the data is out of phase by $-95^{\circ}$ (erroneously suggests negative acoustic impedance for the TopIBR contacts). Bottom: Same section and associated wavelet after the data is zero-phased, showing positive acoustic impedance for the Top-IBR contacts. (c) Left: Wireline logs from basement well penetration Well-KF2 (Data courtesy of TGS), and modeled synthetic seismogram from density and 
sonic logs (not shown here) from Well-KF2 and other basement wells within the study area. Right: Photographs of drill cuttings from the indicated basement depth intervals (Courtesy of the Oklahoma Petroleum Information Center and Chesapeake Energy Reservoir Technology Center). (d) Table 1 showing the results of X-Ray Diffraction (XRD) analysis of the drill cuttings. 

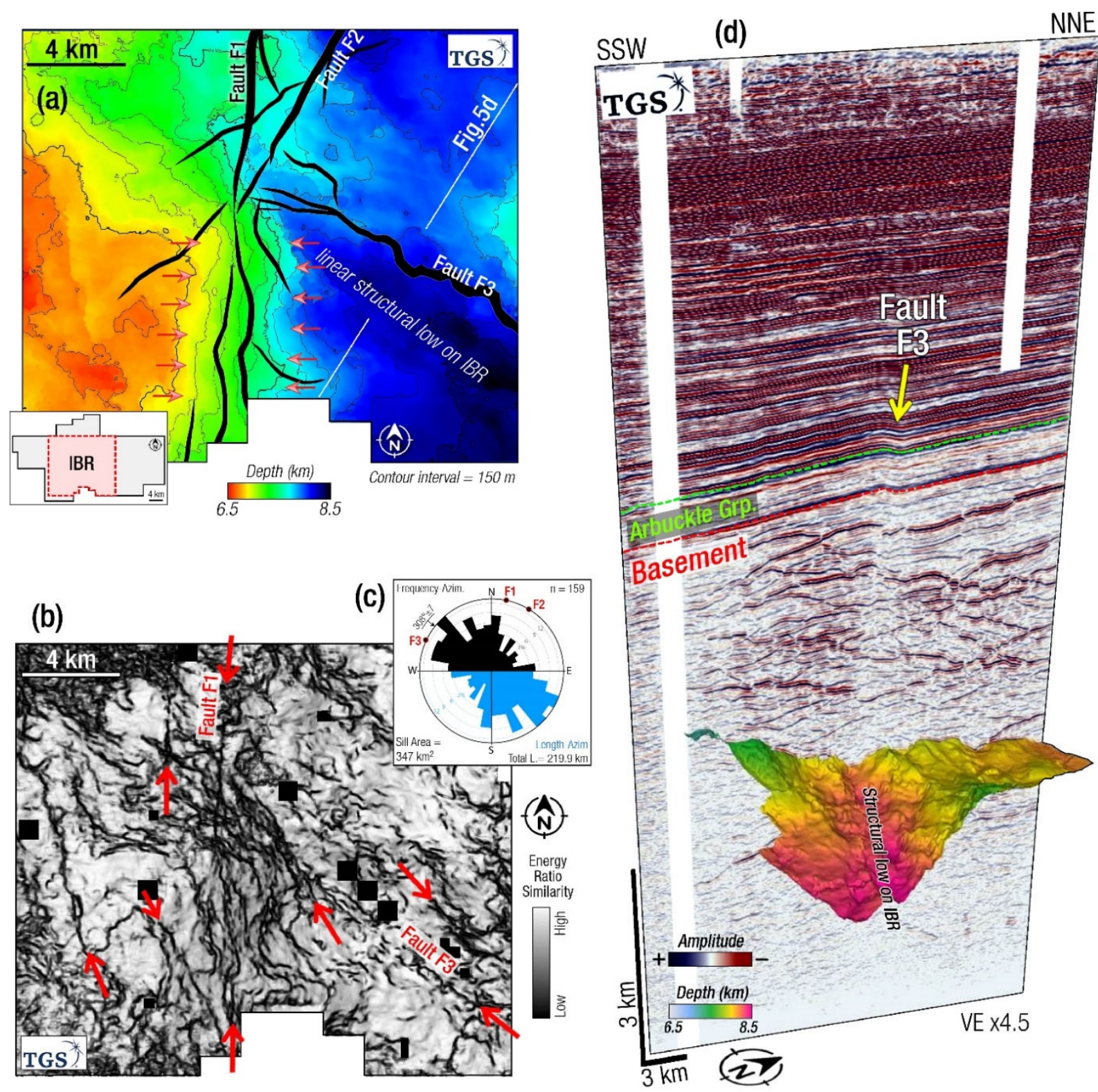

(b)

(c)

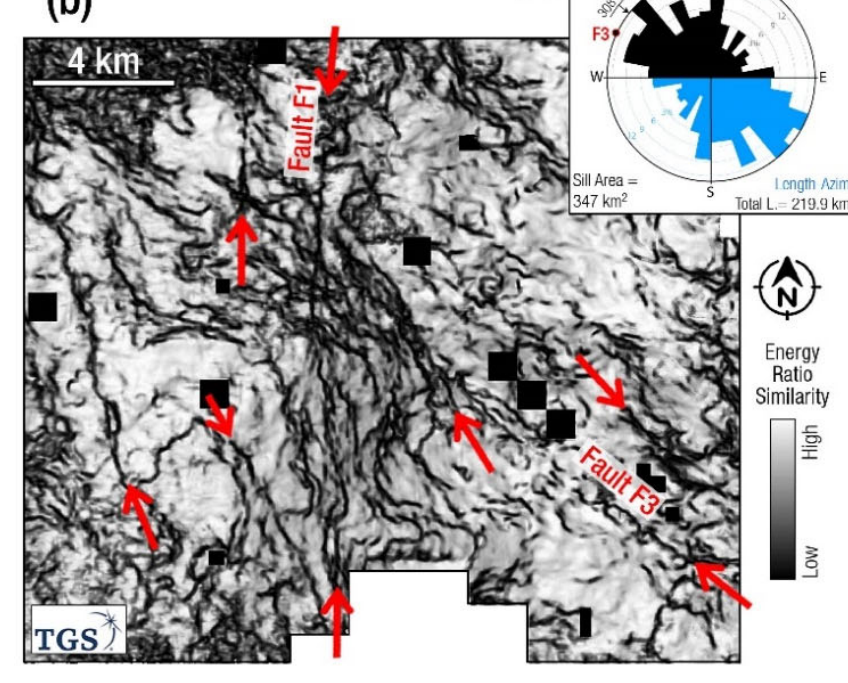

(c)

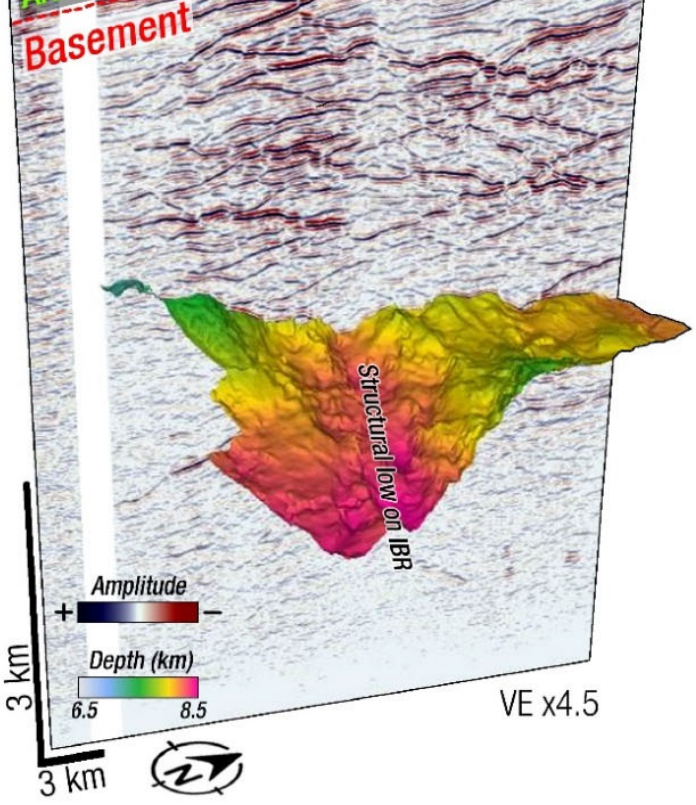

FIGURE 5 (a) Structure map of the mapped extensive deep-seated (6.5-8.5 km depth) intra-basement reflector (IBR) within the seismic survey, overlaid with major Top-Basement faults (black polygons). Red arrows point at N-S topographic gradient near the center of the survey, coinciding with fault F1. (b) Structure map of the IBR (same as 5a) co-rendered with Energy Ratio Similarity (ERS) seismic attribute. The low ERS lineaments represent sub-vertical discontinuity planes at deeper basement depths in the area. Red arrows point at the more rectilinear lineaments which include Fault F1. (c) Rose diagram showing azimuthal and length distribution of the Top-IBR lineaments. Overall, the dominant orientations of the lineaments (NW-SE and N-S) trend parallel to faults F1 and F3. (d) Representative seismic section (looking NW; see 5a for transect) showing the extents and 3D geometry of the IBR surface and relationship between Fault F3 and pronounced NW-SE structurallow on the IBR. 
(a)
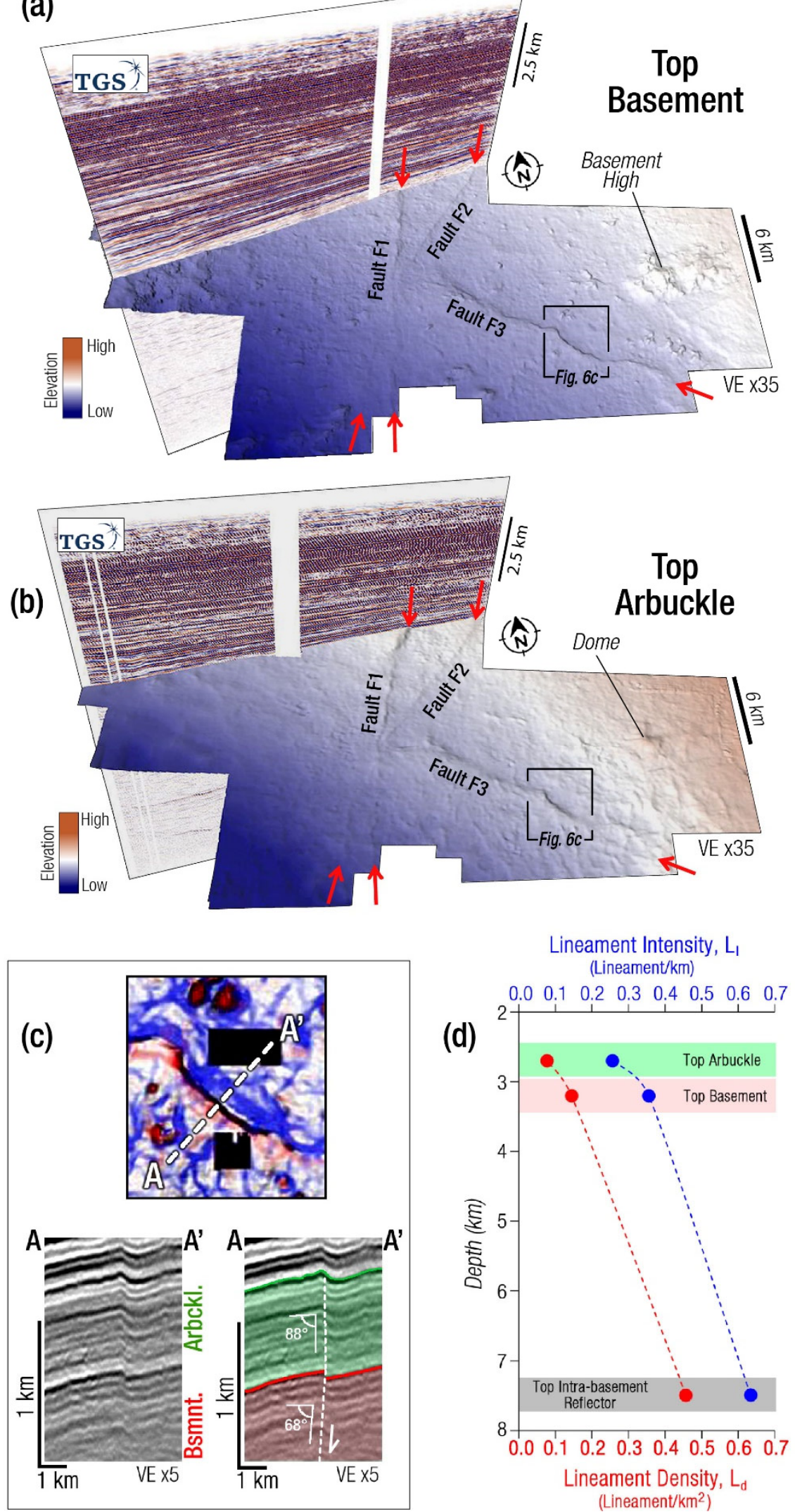

Lineament Intensity, $L_{1}$

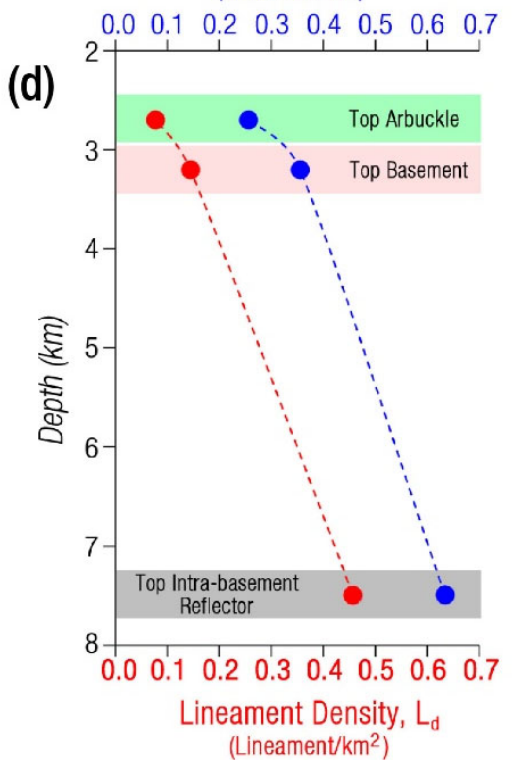


FIGURE 6 (a) Top-Basement structure map with a seismic cross-section showing the large ( $>10 \mathrm{~km}$ long) faults within the study area (faults F1, F2, and F3). (b) Top-Arbuckle structure map with seismic cross-section. Red arrows point to the same large faults observed at the Top-Basement surface. (c) Structure-oriented attribute map (see Figures S3 and S4 for details) of a segment of Fault F3 at the Top-Basement surface, and associated seismic cross-section and interpretation. The map and sections show a change in geometry of deformed reflectors from the Top-Basement into the sedimentary cover. (d) Comparison of the intensity and density of discontinuity lineaments at the Top-Arbuckle ( $\sim 2.7 \mathrm{~km}$ depth), Top-Basement ( $3.2 \mathrm{~km}$ depth) and Top-Intra-basement reflector $(\sim 7.5 \mathrm{~km}$ depth) surfaces. This plot shows relatively greater predominance of the sub-vertical discontinuity planes at depth in the basement compared to the Top-Basement and Top-Arbuckle domains. 

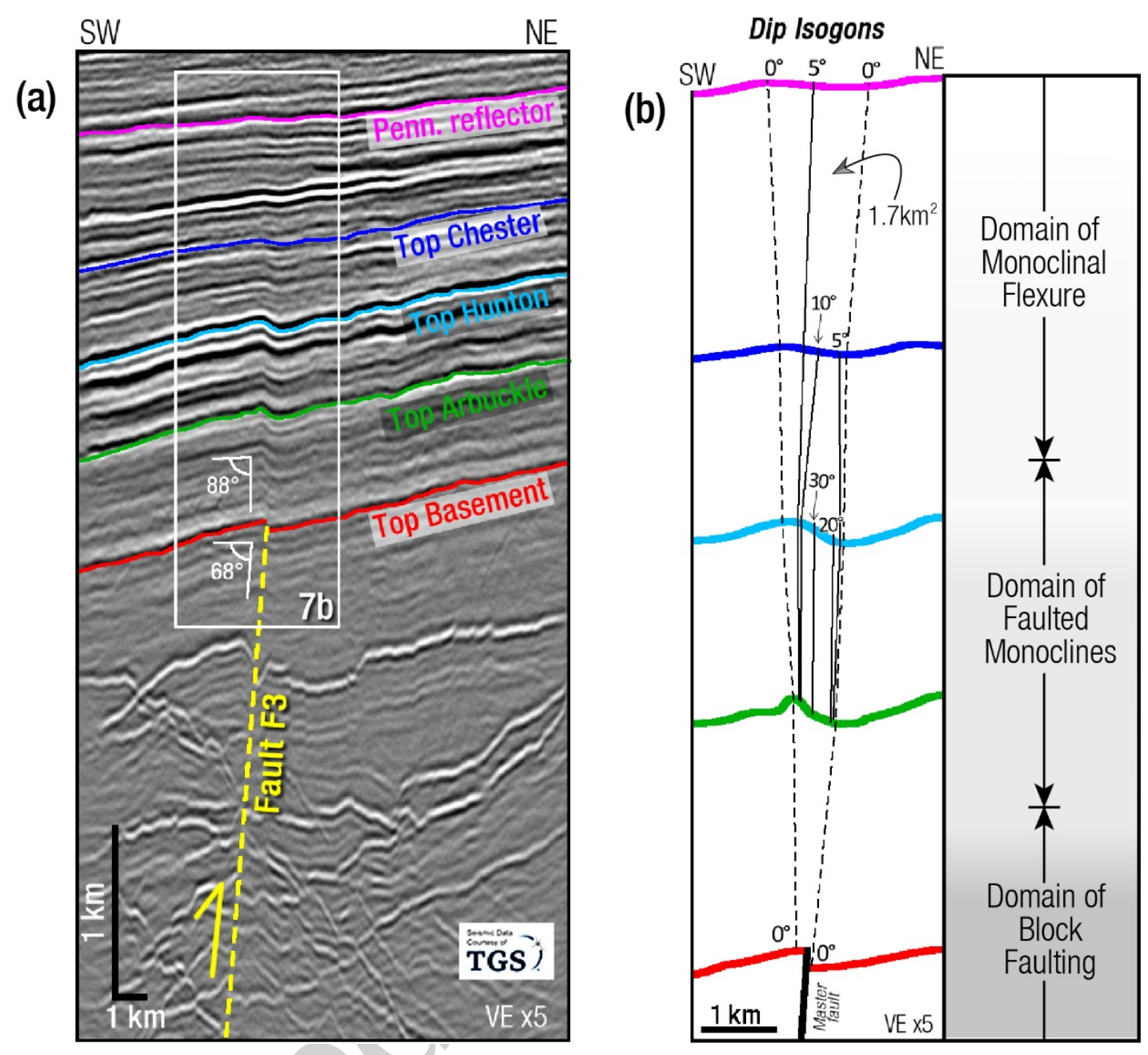

FIGURE 7 (a) Representative seismic section across fault F3 showing the Precambrian to Pennsylvanian interval (same transect as in Figure 3c). (b) Left: Dip isogon pattern for the faulted sequence along fault F3 showing the vertical changes in the geometrical character of the deformed stratigraphic surfaces. The indicated dip values on the dip isogon panel are exaggerated i.e. measured reflector dips at x 5 vertical exaggeration. Right: Interpreted vertical zonation of structural domains above the large basement faults. 
(a)

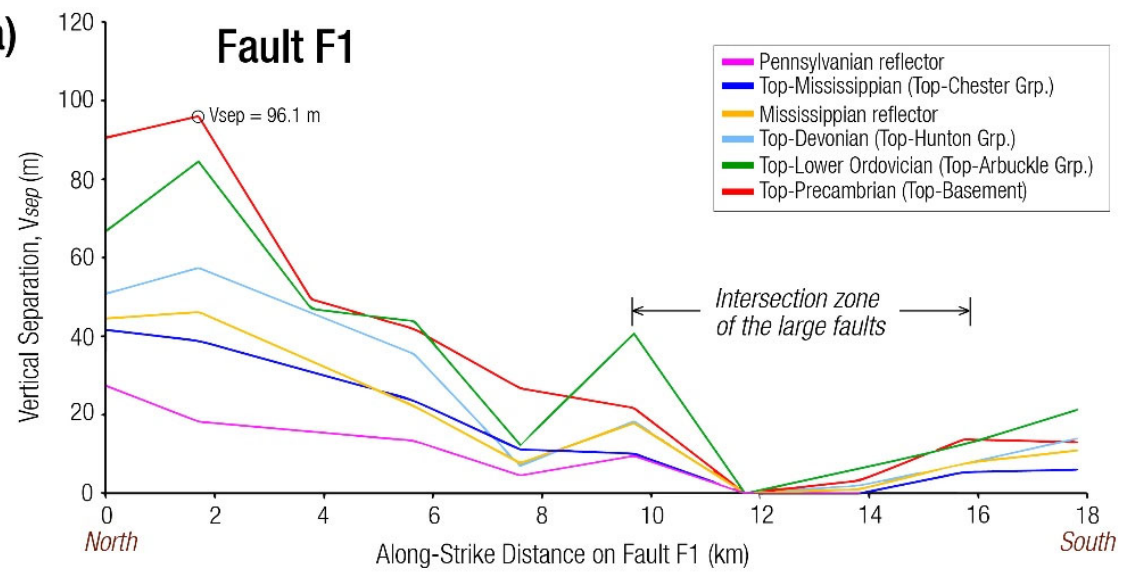

(b)

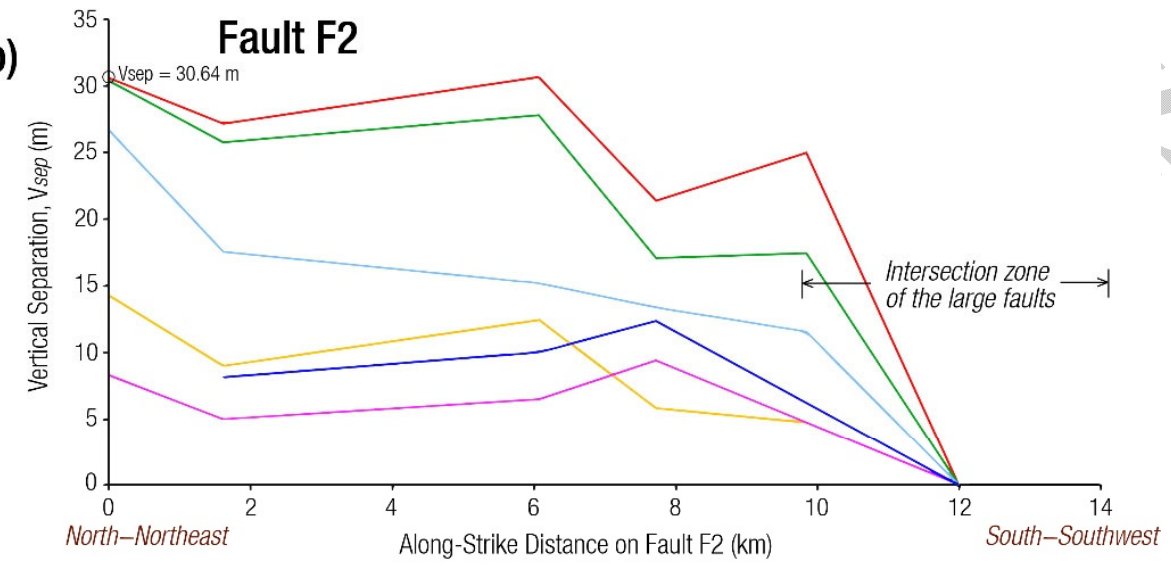

(c)

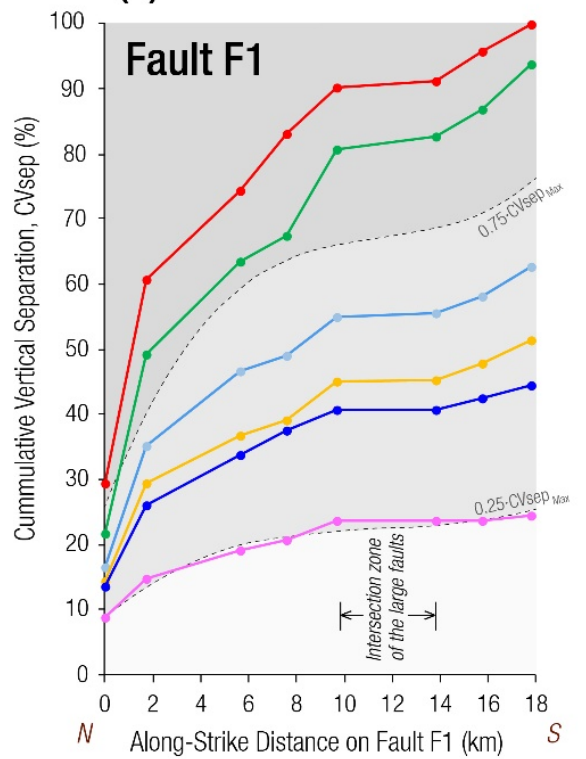

(d)

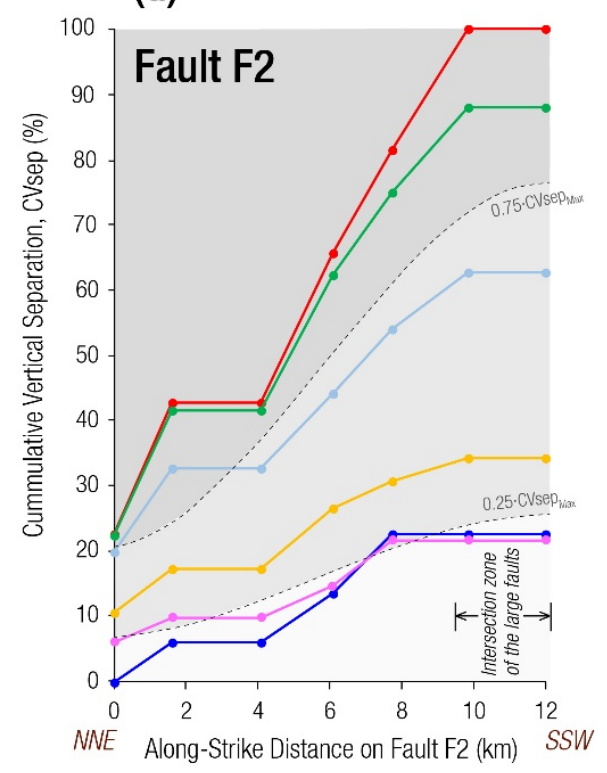

FIGURE 8 Distribution of Vsep versus distance (Vsep-D) along (a) fault F1, and (b) fault F2. Distribution of cumulative Vsep versus distance (CVsep-D) along (c) fault F1, and (d) fault F2. The CVsep-D values are plotted as percentages of the maximum CVsep value of each fault. The greyscale zonation of the plots is based on the $3^{\text {rd }}$ order polynomial fitting curves for the $25 \%$ CVsep $_{\text {max }}$ and $75 \%$ CVsep $_{\text {max }}$ at each measurement location. 
(a) Vertical Separation, Vsep (m) on Fault F1

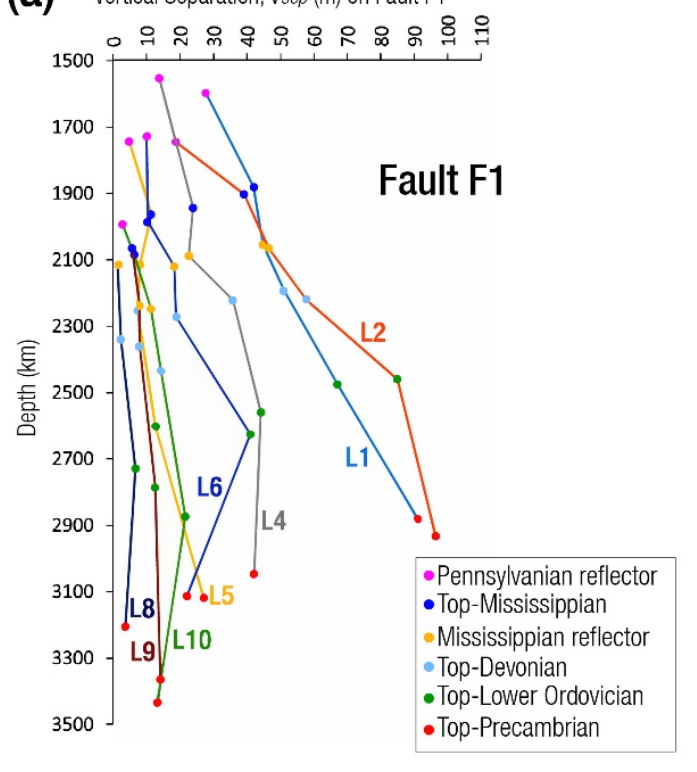

(b) Vertical Separation, Vsep (m) on Fault F2

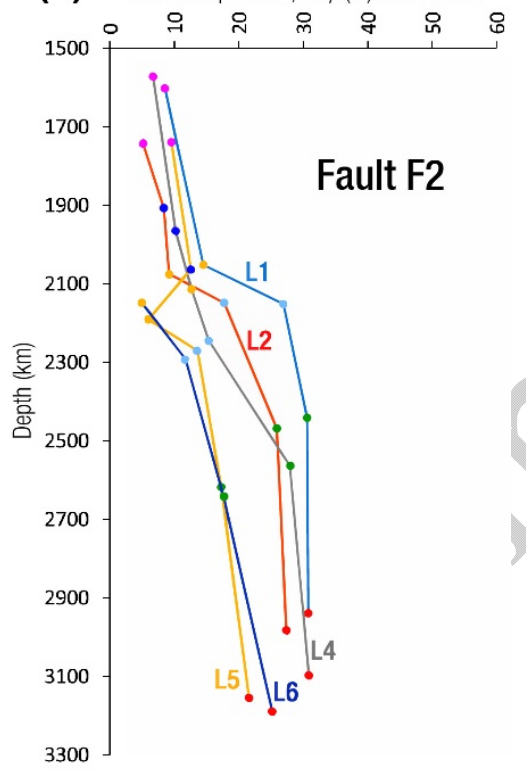

(c)
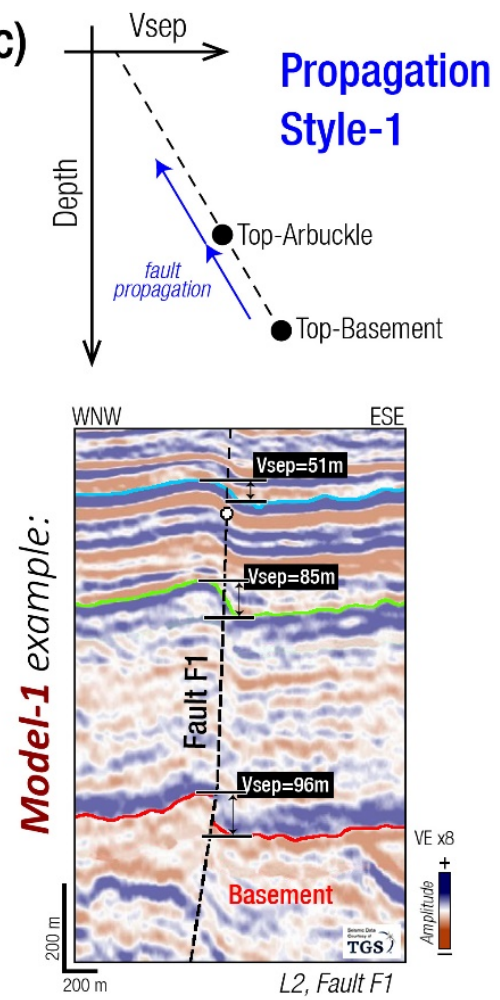

(d)
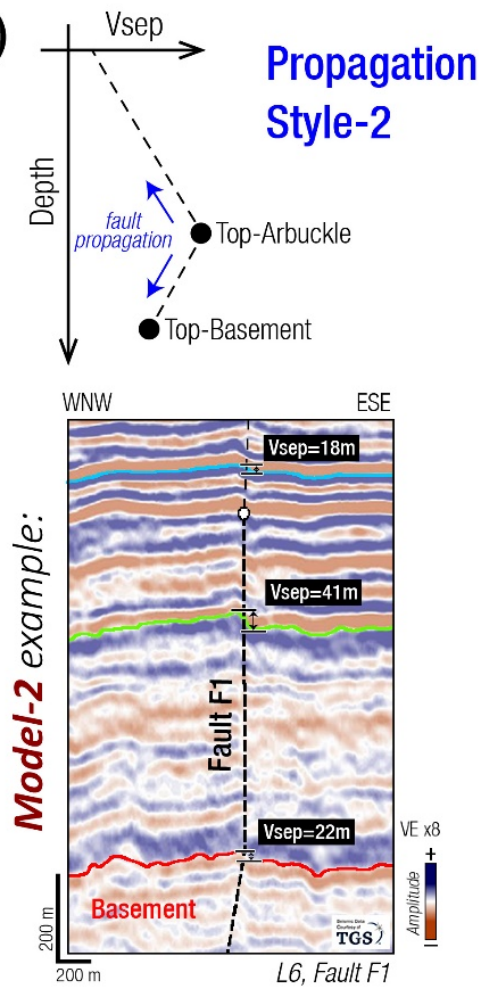

FIGURE 9 Vertical separation versus Depth (Vsep-Z) distribution along (a) fault F1, and (b) fault F2. See Figure $6 \mathrm{c}$ for the measurement locations. Vsep-Z models inferred from the observed trends in Figures 9a-b, in which (c) Style-1 describes basement-driven propagation of fault deformation, and (d) Style-2 describes intrasedimentary-driven nucleation and propagation of fault deformation. The associated seismic sections show an example of each propagation style. 


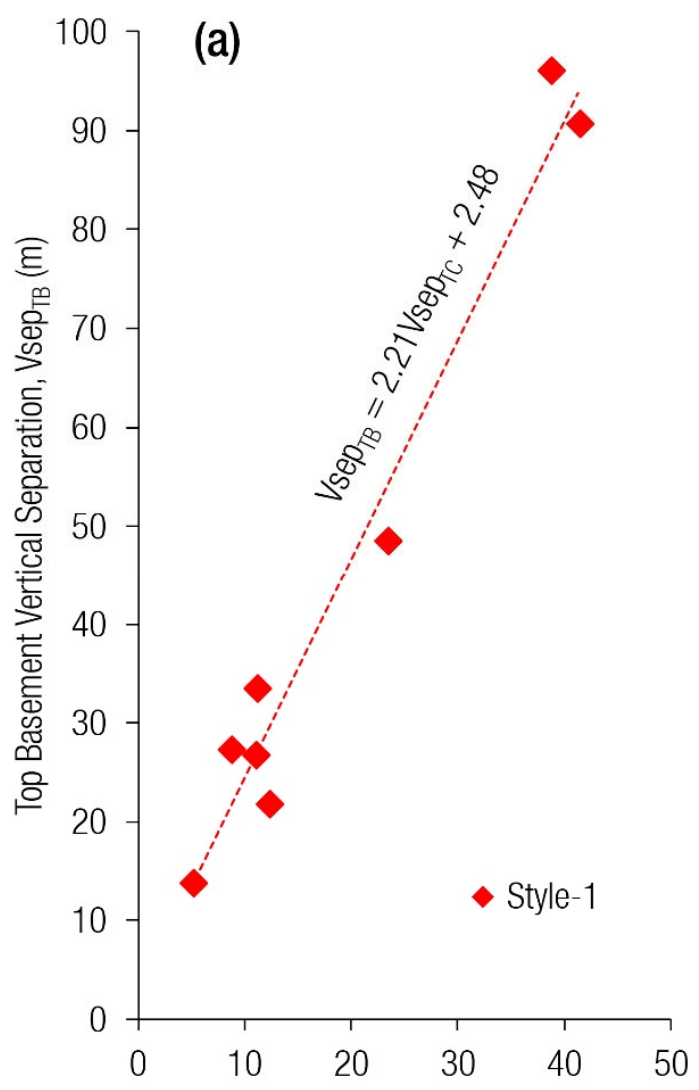

Top Chester Vertical Separation, Vsep $_{\text {TC }}(\mathrm{m})$

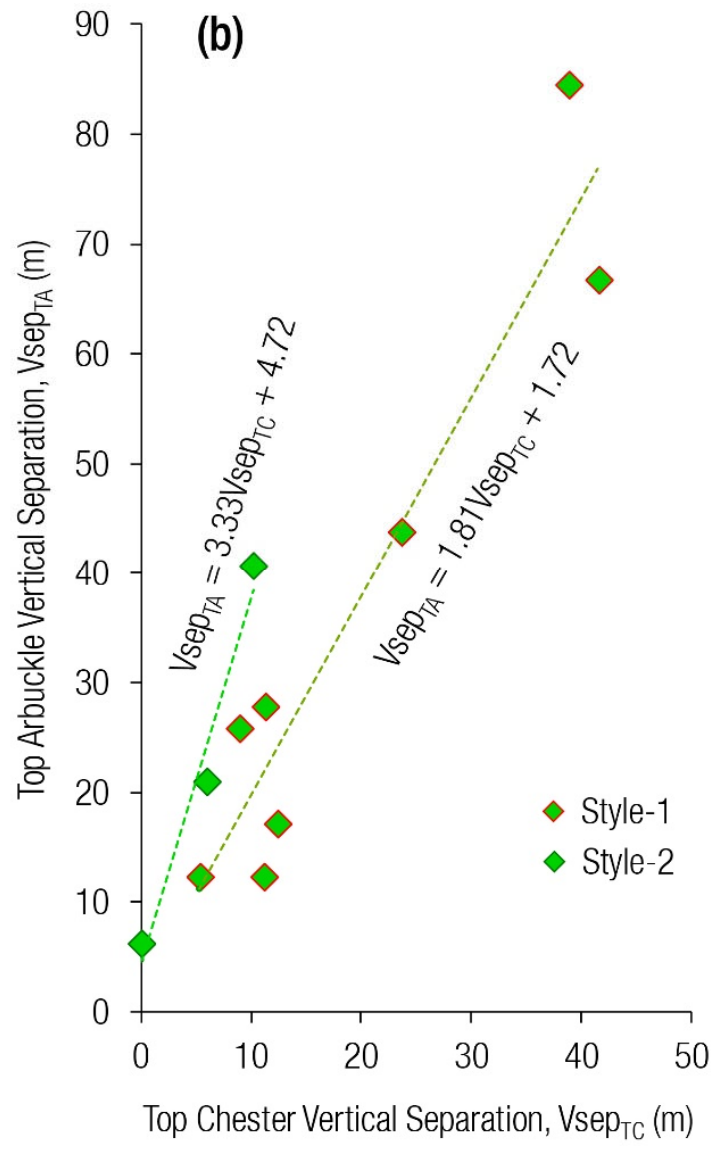

FIGURE 10 Efficiency of the vertical fault propagation styles. (a) Plot of Top-Basement Vertical Separation (Vsep ${ }_{\text {Тв}}$ ) versus Top-Chester Vertical Separation (Vsep ${ }_{\mathrm{TC}}$ ) for Style-1 trend. (b) The plots of Top-Arbuckle Vertical Separation (Vsep ${ }_{\mathrm{TA}}$ ) versus Top-Chester Vsep $\mathrm{T}_{\mathrm{TC}}$ for Style-1 and Style-2 trends. The plots suggest that basement-driven propagation of deformation (Style-1) has a relatively greater efficiency of propagating deformation to shallower depths compared to sedimentary-driven deformation (Style-2). 
(a)

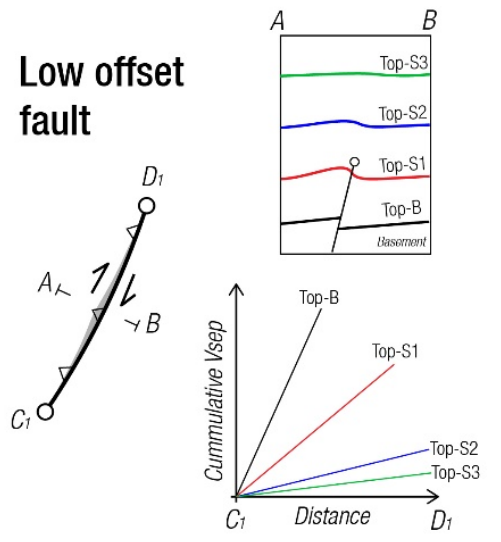

(b)

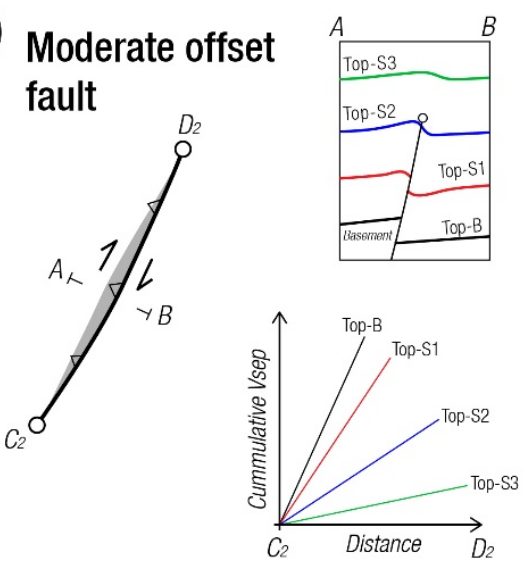

(c) High offset fault
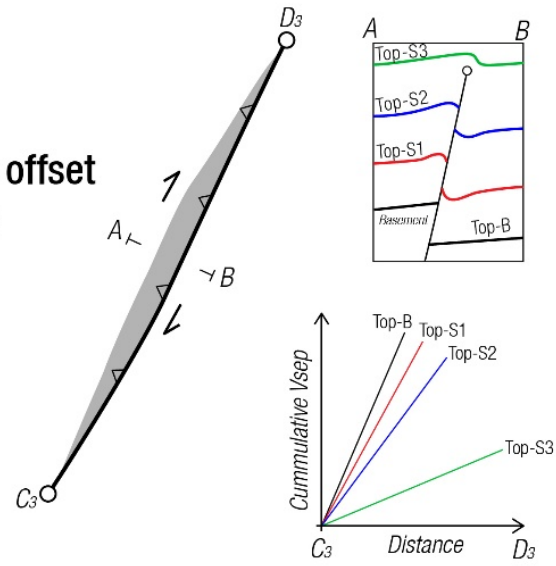

(d)

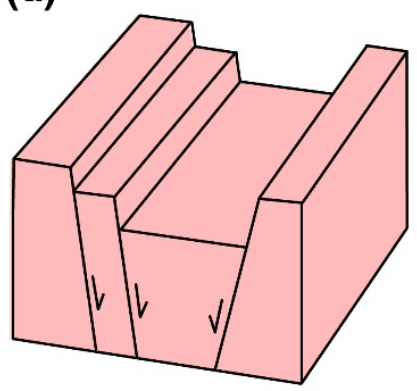

STAGE 1:

Development of steep basement faults bounding horsts \& grabens of the the Mid-Continent Rift in the Precambrian (hypothetical).

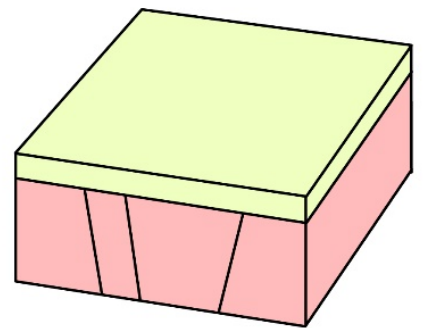

STAGE 2:

Erosion of the top basement and deposition of sedimentary rocks in the Early to Mid Paleozoic.

$\square$ Paleozoic sedimentary rocks

$\square$ Precambrian igneous rocks

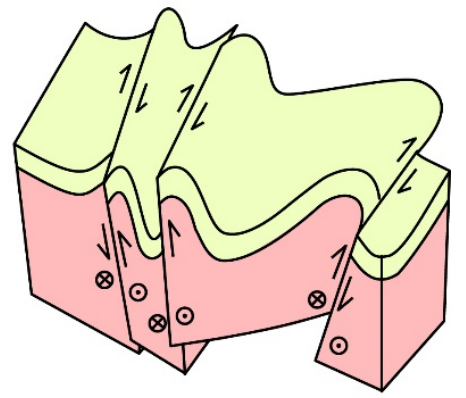

STAGE 3:

Late Paleozoic transpressional reactivation of the basement faults create folding and faulting of sedimentary cover rocks.

FIGURE 11 (a-c) Schematic models based on the observed distribution of cumulative vertical separation with distance (CVsep-D) along faults F1 and F2 (see Figures 8c-d). The plan-view fault traces represent the deepest stratigraphic surfaces (e.g. Top-B and Top-S1). The figures describe how the clustering of the CVsep-D curves changes with the accrual of offset on a propagating basement- 
rooted transpressional fault. (d) Cartoons summarizing a hypothesized evolution of the basementinvolved deformation of the sedimentary cover of the Anadarko Shelf, Oklahoma. 


\section{SUPPLEMENTARY FIGURES}

(a)

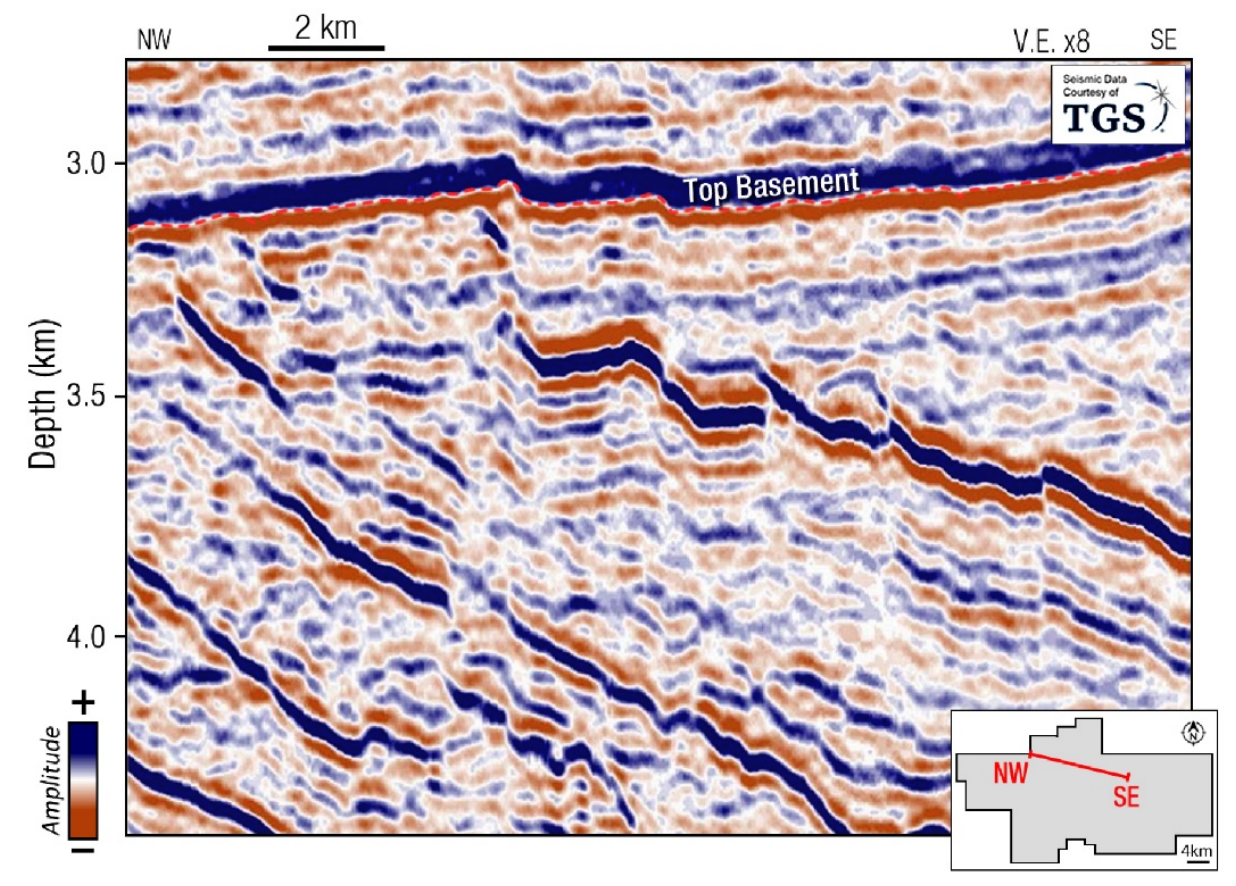

(b)

TABLE 2: X-Ray Fluorescence (XRF)

\begin{tabular}{|c|c|c|c|}
\hline & Sample A & Sample B & Sample C \\
\hline Mg wt $\%$ & 1.8638 & 2.1592 & $\mathrm{BDL}$ \\
\hline Al wt \% & 4.1302 & 4.4637 & 5.0358 \\
\hline Si wt $\%$ & 22.3335 & 13.7566 & 25.6265 \\
\hline $\mathrm{P}$ wt\% & BDL & $\mathrm{BDL}$ & BDL \\
\hline S wt $\%$ & $\mathrm{BDL}$ & BDL & $\mathrm{BDL}$ \\
\hline $\mathrm{K} w t \%$ & 2.4284 & 0.8374 & 2.5593 \\
\hline Ca $w t \%$ & 3.5491 & 4.8771 & 1.5094 \\
\hline Ba wt $\%$ & $\mathrm{BDL}$ & $\mathrm{BDL}$ & $\mathrm{BDL}$ \\
\hline Ti wt $\%$ & $\mathrm{BDL}$ & 0.47 & 0.121 \\
\hline V wt\% & $\mathrm{BDL}$ & $\mathrm{BDL}$ & BDL \\
\hline Cr wt $\%$ & 0.0058 & 0.0028 & 0.0063 \\
\hline Mn wt\% & 0.038 & 0.0671 & 0.0453 \\
\hline Fe wt $\%$ & 0.5935 & 4.6826 & 1.3172 \\
\hline Ni wt $\%$ & 0.0053 & 0.0026 & 0.0061 \\
\hline Cu wt $\%$ & $\mathrm{BDL}$ & 0.0033 & $\mathrm{BDL}$ \\
\hline Zn wt $\%$ & 0.0151 & 0.0079 & 0.0131 \\
\hline Th wt\% & $\mathrm{BDL}$ & $\mathrm{BDL}$ & $\mathrm{BDL}$ \\
\hline$R b$ wt $\%$ & $\mathrm{BDL}$ & $\mathrm{BDL}$ & $\mathrm{BDL}$ \\
\hline $\mathrm{U} w \mathrm{wt} \%$ & $\mathrm{BDL}$ & $\mathrm{BDL}$ & BDL \\
\hline Sr wt $\%$ & BDL & 0.0167 & $\mathrm{BDL}$ \\
\hline$Y w t \%$ & 0.0027 & 0.0021 & 0.0022 \\
\hline Zr wt\% & 0.0099 & 0.0071 & 0.0081 \\
\hline $\mathrm{Nb} w t \%$ & 0.0012 & 0.0005 & 0.0009 \\
\hline Mo wt\% & 0.0043 & 0.0059 & 0.0045 \\
\hline
\end{tabular}

\section{(c)}

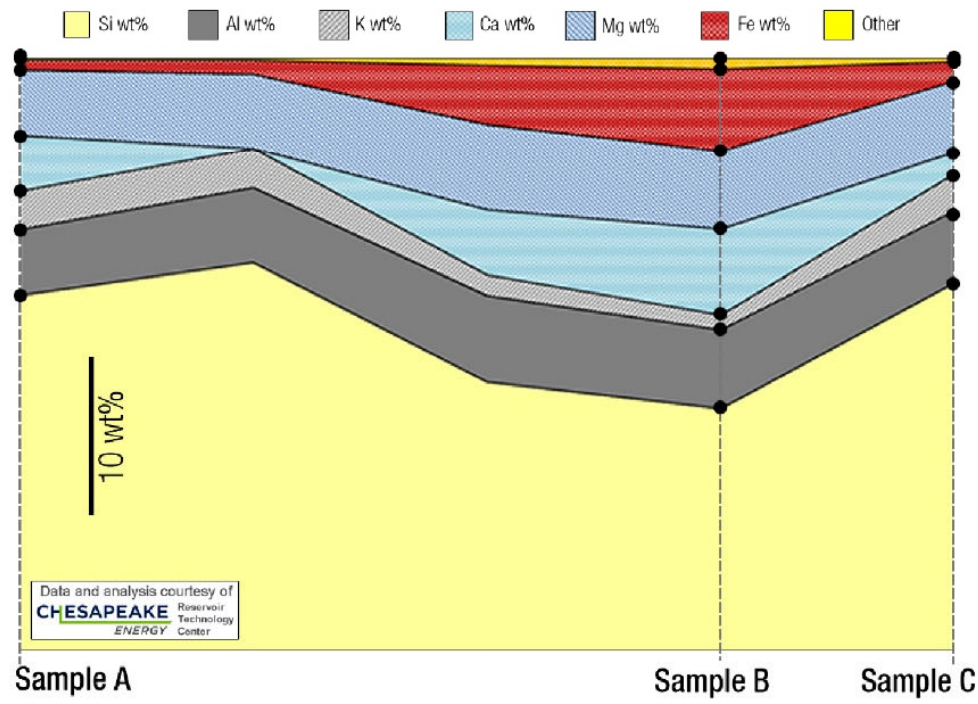

XRF data and plot are courtesy of the Chesapeake Energy Reservair Technology Center

FIGURE S1 (a) An uninterpreted version of the seismic cross-section presented in Figure 4a. (b) Table 2 and (c) Plot showing X-Ray Fluorescence (XRF) analyses of the drill cuttings. XRF (this figure) and XRD (Figure 4d) data are courtesy of the Chesapeake Energy Reservoir Technology Center. 


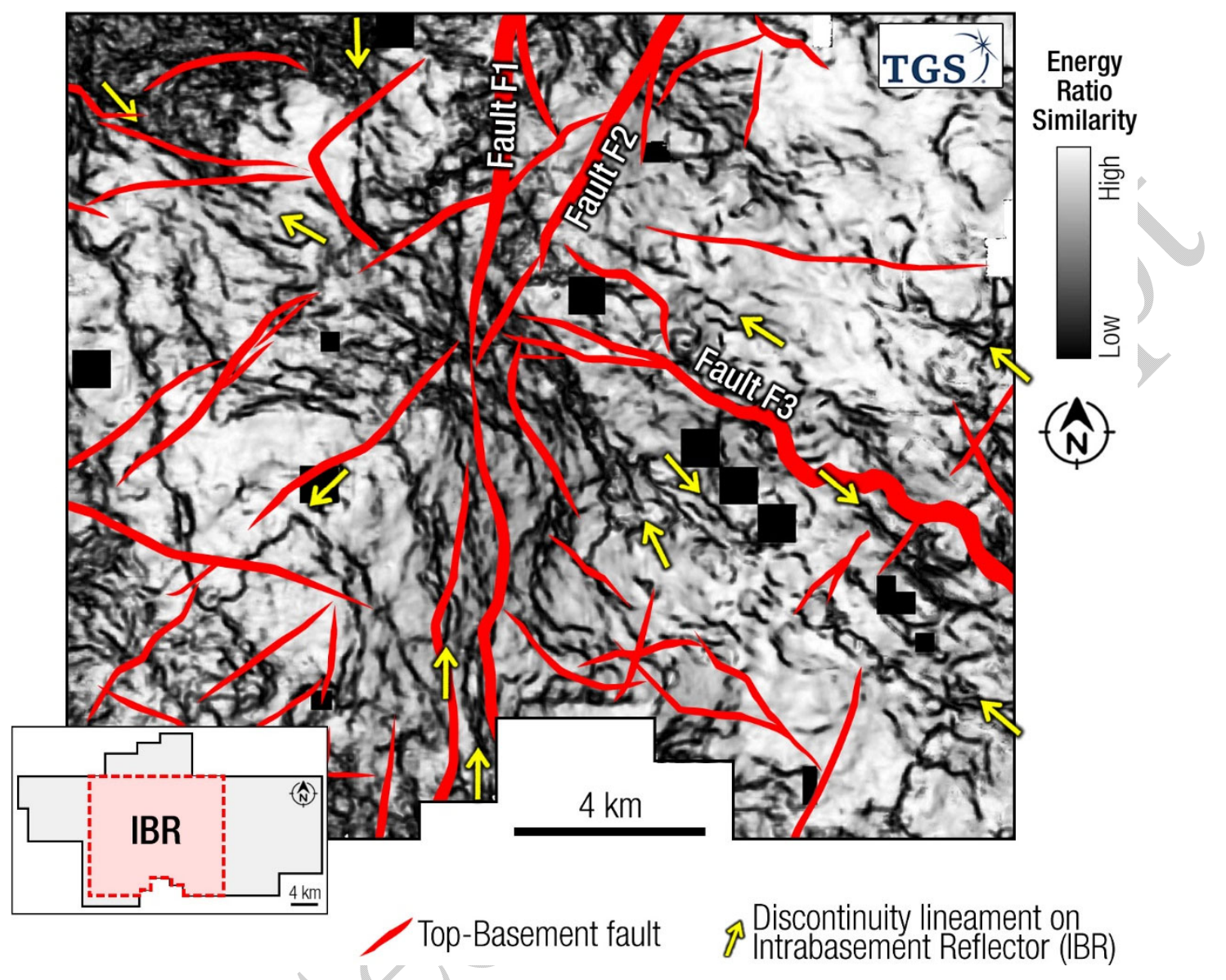

FIGURE S2 Surface map of the mapped intrabasement reflector (IBR) rendered with the Energy Ratio Similarity seismic attribute. Red polygons represent interpreted Top-Basement fault lineaments. Yellow arrows point at rectilinear discontinuity lineaments. 


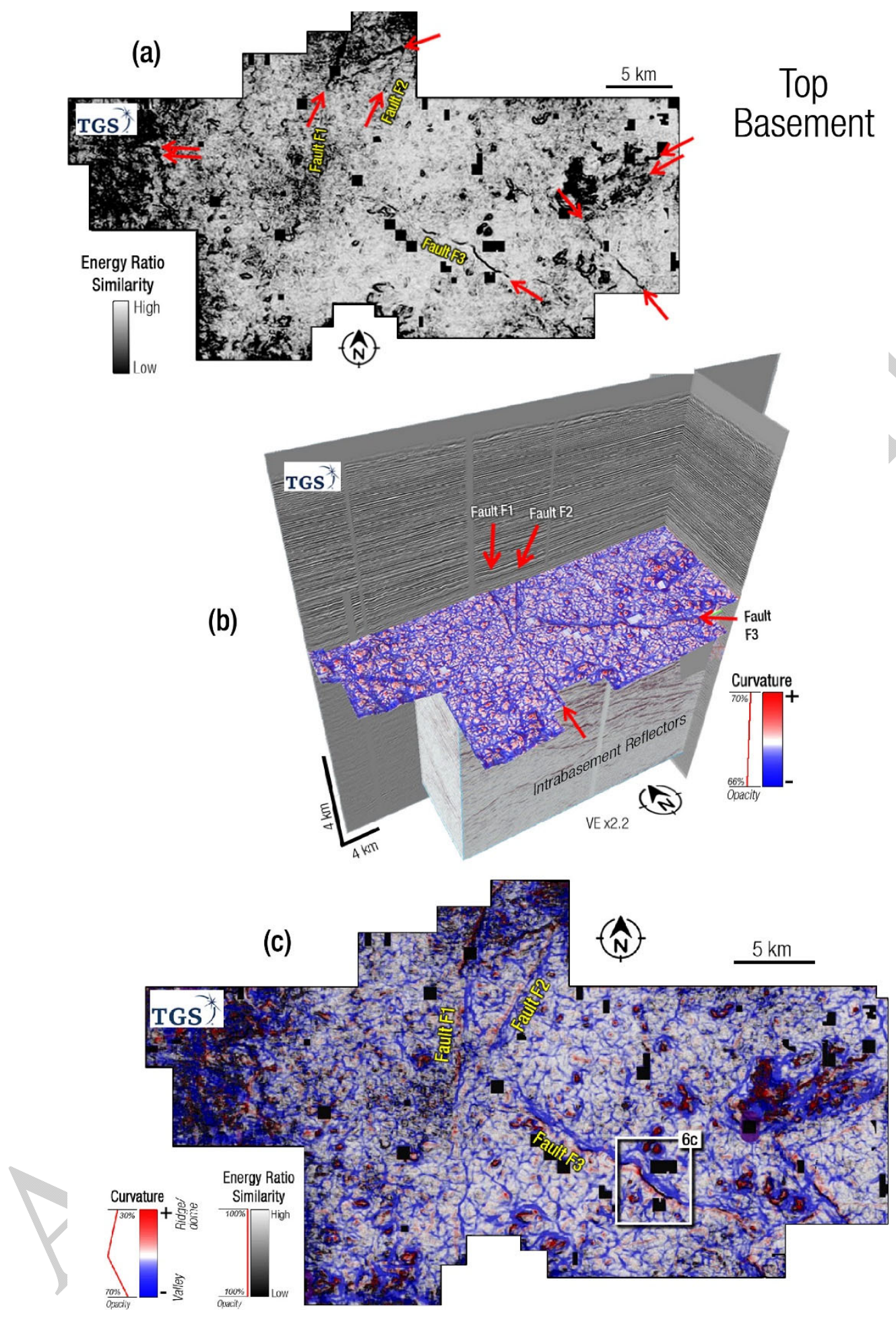

FIGURE S3 (a) Top-Basement surface rendered with Energy Ratio Similarity attribute. (b) Chair display showing Top-Basement rendered with most-positive $(k 1)$ and most-negative $(k 2)$ curvature attribute. (c) Top-Basement surface rendered with Energy Ratio Similarity and curvature attributes. Red arrows point at fault lineaments. 

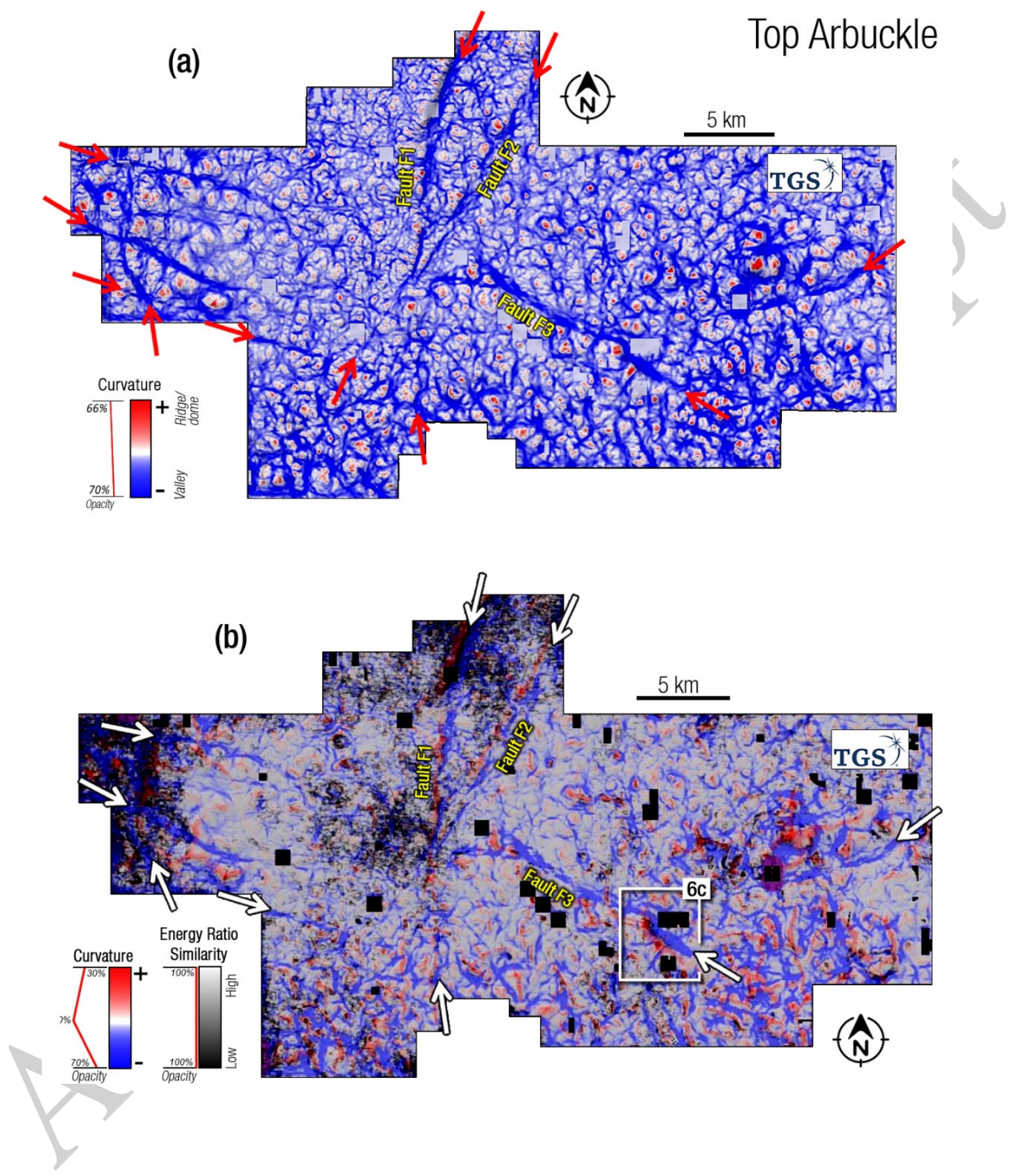

FIGURE S4 (a) Top-Arbuckle surface rendered with most-positive ( $k 1)$ and most-negative $(k 2)$ curvature seismic attributes. Red arrows point at fault lineaments. (b) Top-Arbuckle surface rendered with most-positive $(k 1)$, most-negative $(k 2)$ curvature and energy ratio similarity attributes. 
(a) Fault F1

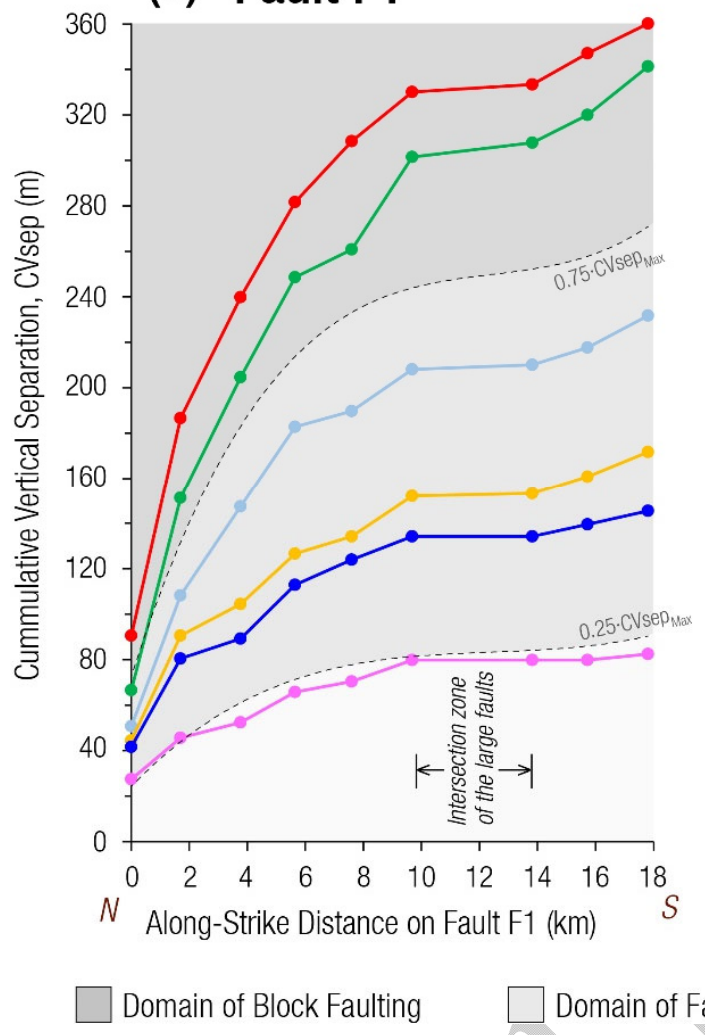

(b) Fault F2

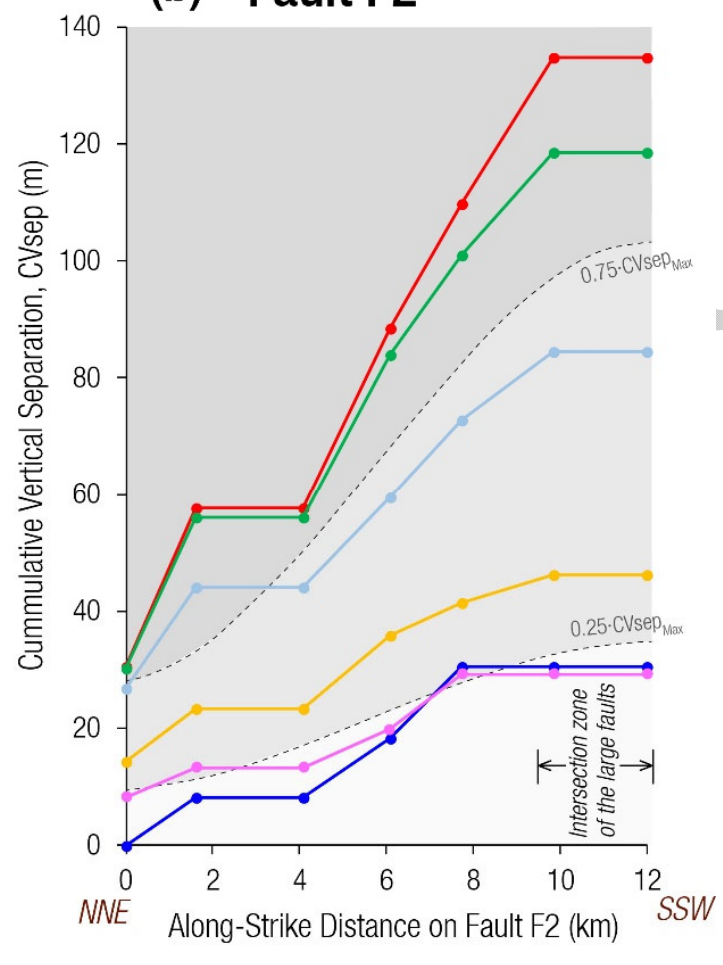

FIGURE S5 Distribution of cumulative Vsep versus distance (CVsep-D) along (c) fault F1, and (d) fault F2. The greyscale zonation of the plots is based on the $3^{\text {rd }}$ order polynomial fitting curves for the $25 \%$ CVsep $_{\max }$ and $75 \% \mathrm{CVsep}_{\max }$ at each measurement location. 